Please cite this article as:

Ünal, E., Urbinati, A., Chiaroni, D. and Manzini, R. (2019).

Value Creation in Circular Business Models: The Case of a US Small Medium Enterprise in the Building Sector.

Resources, Conservation and Recycling, Vol. 146, pp. 291-307.

(DOI: https://doi.org/10.1016/j.resconrec.2018.12.034) 


\title{
Value Creation in Circular Business Models: The Case of a US Small Medium Enterprise in the Building Sector
}

\begin{abstract}
The circular business model represents a holistic system of co-evolving managerial practices for collective value creation, delivery and capture, which provide solutions for sustainable development. Previous research on circular business models aimed to understand value creation mostly in terms of a single managerial practice or in a relatively isolated manner. In particular, little is known regarding the system of managerial practices that creates value. Accordingly, this study proposes a theoretical framework characterized by a set of managerial practices in connection with relevant internal and external contextual factors for creating value within a circular business model. The framework was tested in a specific case of a small medium-sized enterprise (SME) operating in a building sector, which can be considered a great example of circular economy put into practice. Therefore, the explorative nature of the case allows for deep probing that helps consolidating the framework. Among the main results, essential outcomes included configuring and adapting the company's business model to particular internal and external contextual factors; valorization of local waste by harmonizing managerial practices, and socio-cultural and socio-economic settings, as well as sustainable behaviours among the actors of supply chain. This study contributes to the field of circular business model research by adopting a broader, interdisciplinary approach toward the concept of value creation. Further, it provides managers with a roadmap for creating value by enhancing the degree of circularity within a given context.
\end{abstract}

Key words: Circular Economy, Circular Business Model, Value Creation, Contextual Factors, Building Sector, Sustainability.

\section{Introduction}

Circular economy has become a debated topic in the strategic management field, as it provides many opportunities for academia, policy makers and business. As such, the business domain has mainly adopted the concept of circular economy as a lever for new ways of creating value, which is a core dimension of their business model (Bocken et al., 2018; Manninen et al., 2018). Accordingly, this study aims to present a deeper understanding of value creation in circular business models by proposing a theoretical framework that incorporates a system of managerial practices in connection with relevant contextual factors.

The antecedents of the circular economy approach are found in the fields of industrial ecology and cradle-to-cradle (C2C), mainly focusing on closed-loop flows of materials and a novel design for products (McDonough and Braungart, 2002; Stahel, 1994). The core idea of circular economy is the decoupling of economic growth from natural resources and negative social impact (Murray et al., 2015). Similarly, it has been studied as a sustainable development initiative (Korhonen et al., 2018) that represents "new concepts of system, economy, value, production, and consumption" (Murray et al., 2015, p.373). Indeed, several contributions into 
this research stream point to the circular business model, which investigates the managerial practices that companies implement to create, deliver, and capture value (Lewandowski, 2016; Rizos et al., 2016). Previous research studied circular business models and value creation mostly as implementation of a single practice or in an isolated manner (De los Rios and Charnley, 2017; Leising et al., 2018; Tukker, 2013). Additionally, by adopting a historical perspective, Peck's (2016) framework stresses that the circular economy requires many actors - societal, policy and business - to cooperate to realize the transition. However, little is known regarding the system of managerial practices that creates value within a circular business model, in connection with internal and external environmental factors influencing the business of a firm. This gap is particularly crucial when considering that the execution of a business model spans firm's boundaries and is highly contingent upon the context (Amit and Zott, 2001; Teece, 2017). Furthermore, the circular business model literature suffers from the lack of clear definition of the business model ontology and the variables that constitutes a viable business model (Bouwman et al., 2018; Haaker et al., 2017).

In particular, most recent studies in the research stream of circular business models have highlighted two main dimensions of business models that companies can leverage to implement circular economy principles (Urbinati et al., 2017a). On one hand, the value network dimension concerns creating value by managing the supply chain and its key relationships with suppliers, manufacturers and retailers (Goldsworthy, 2013; Parkinson and Thompson, 2003; Vermeulen, 2015). On the other hand, the customer value proposition and interface dimension concerns capturing value by managing relationships with clients, reinforced by new mechanisms of transferring value, such as pay-as-a-service or servitization (Tukker, 2013; Visnjic et al., 2018; Williams, 2007). Focusing on circular business model is very relevant today as the role of companies is changing dramatically as a response to the social, environmental and economic pressures. Furthermore, according to Geissdoerfer et al. (2018a, 2018b), circular business models have an imperfect overlap with sustainable business models, which have been described as extension of conventional business models that integrate sustainability goals and principles into the value proposition, value creation and capture. As for circular business models, the authors suggest that: "circular business models are not only creating sustainable value, employing proactive multi-stakeholder management, and have a long-term perspective, but also close, slow, intensify, de-materialize, and narrow resource loops" (p.405). Consequently, circular business models provide several new perspectives in terms of value creation and capture that needs to be analysed in-depth.

Thus, this paper mainly leverages and refines the value network dimension presented in the theoretical taxonomies for circular business models (Urbinati et al., 2017; Unal, et al., 2018) to understand how value is created. These taxonomies offer a more comprehensive view of the phenomenon of circular business model implementation as they have a level of detail in the selection of the managerial practices that fits with the purpose of this study. Accordingly, these taxonomies, which are further detailed hereafter, were chosen by the authors as research protocol of the study and used to propose the theoretical framework to be further used as guide for the empirical investigation. In particular, the proposed theoretical framework firstly emphasizes the Design for X practices: Design for Recycling (DfR), Design for Remanufacturing and Re-use (DfRe), Design for Disassembly (DfD), and Design for Environment (DfE). Then, it examines both the role of the managerial commitment to enable the transition and the actions of the key supply chain partners to push the shift toward a circular business model. Secondly, the framework takes into account the most recent contributions in business-model innovation to 
investigate the internal contextual factors that can be incorporated into the value network dimension of a circular business model and reinforce the prominence of Design for X practices, the role of key supply chain partners and that of the managerial commitment. Finally, it adds external contextual factors that capture industry-, country- and society-level conditions characterizing the context, which can significantly influence the extent by which a circular business model is designed or reconfigured. Indeed, business models require continuously evolving scenarios to innovate their main dimensions to respond to environmental changes and new demands (Hueske et al., 2015). Thus, our theoretical conceptual framework address specific internal and external contextual factors. Internal factors include: strategic orientation; industrial capabilities; learning and training mechanisms; and company age and size. External factors refer to geography (local and cultural settings); level of market competition; and the regulatory framework characterizing the context.

Starting from the above premises, we aim to answer the following research questions (depicted in Figure 1):

- Research Question 1 (RQ1): "How do contextual factors influence the extent to which value is created in a circular business model?"

- Research Question 2 (RQ2): "Which managerial practices do companies implement in the value network dimension of their circular business model for value creation and how they mediate the influence of the contextual factors on value creation?"

In order to answer to these research questions, we propose a preliminary research model (also depicted in Figure 1) that follows the research gaps and questions above. The model was especially developed by leveraging the existing business model literature. For instance, Bouwman et al. (2018) suggested that business model practices have the mediating role between the context and overall performance of the company. And it can be said that this is the common approach in strategic management field. Accordingly, having this in mind, we have perceived the value creation as one of the dimensions concerning the overall performance of the company. Thus, we pursued at understanding the role of the context and the mediating effect of the managerial practices on value creation in circular business models. In addition, following the definition of managerial practices given by Bouwman et al., (2018), as a means to express the strategy of a company in its business model and the way that strategy of the company is operationalized, in our paper, we intend business model managerial practices the way top management, usually in charge of defining and modifying over time the strategy of the company, makes the transition to a circular business model.

\section{$R Q 1$}

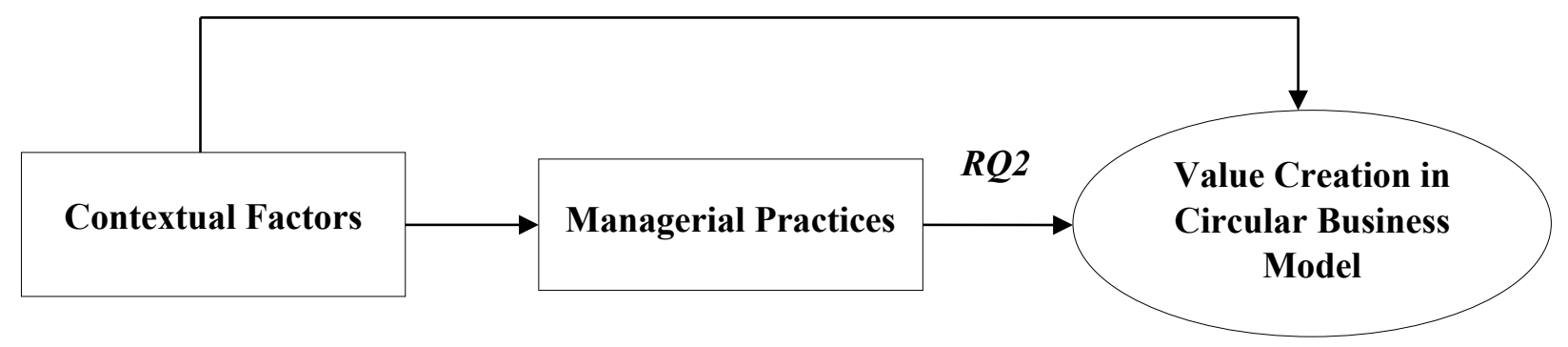

Figure 1. Gaps in the existing research. 
This paper is exploratory in nature, and its single case-study methodology analyzes a US smallmedium-sized enterprise (SME) operating in the building sector. This sector is particularly interesting from the perspective of the circular economy (Bourguignon, 2016; Leising et al., 2018). Several research contributions highlight the increasing need for quality retrofitting and sustainable new construction to increase the percentage of materials recycled or reused at the end of a building's lifecycle (Leising et al., 2018). Therefore, all partners involved in establishing (circular) buildings that are "designed, planned, built, operated, maintained, and deconstructed in a manner consistent with CE principles" (Pomponi and Moncaster, 2017, p.711) should consider implementing practices that reshape the design of their supply chain and build their own circular business model. Such partners would include suppliers of raw materials, manufacturers, retailers, and designers.

This issue is even more relevant nowadays, as "buildings accounted for 32 percent of total global final energy use in 2010. Moreover, the building industry consumes 40 percent of the materials entering the global economy (Khasreen et al., 2009), while only an estimated 20 percent to 30 percent of these materials are recycled or reused at the end of life of a building" (Leising et al., 2018, p.977). However, the building sector is rather unexplored, given its relevance in terms of stocks and flow of materials (Lieder and Rashid, 2016; Tukker, 2015). Moreover, existing studies mainly focus on technical materials, with less focus on the biological cycle (Leising et al., 2018; Pomponi and Moncaster, 2017).

We aim to illuminate a set of managerial practices in light of particular internal and external contextual factors a company in this industry is required to manage to foster the creation of value in its own circular business model and establish circular buildings. In other words, we delve into effective management of the supply chain to reduce energy- and resource-demanding materials for circular buildings. Our research advances existing knowledge in the field of circular economy research. In addition, this study places a clear attention on the company and its choices of business model design for value creation as unit of analysis in the context of circular economy implementation in building industry. The research allows for understanding the potential implementation of circular economy in the under-explored sector of buildings in the US context. In addition, the results provide a set of insights for managers, particularly those in charge of sustainability and environmental responsibility. This paper further gives examples of managerial practices implementation for creating value in circular business models in the building sector.

The paper is structured as follows. Section 2 presents the background of the existing research - including the conceptual development (Section 2.1), the research protocol (Section 2.2) and the theoretical framework, which will be used to address the empirical analysis (Section 2.3). Section 3 presents the single case-study methodology and briefly presents the case of a US SME operating in the building sector. Section 4 then summarizes the results, and Section 5 discusses the main findings of our research. Finally, Section 6 draws the conclusions and limitations of the paper, including avenues for further research in the field of circular business models. 


\section{Background of existing research}

The research on circular economy finds its antecedents into the fields of industrial ecology and $\mathrm{C} 2 \mathrm{C}$, and focus on optimizing industrial systems and novel designs for products and technical materials (McDonough and Braungart, 2002; Stahel, 1994). To this end, circular economy realizes two material cycles: the technical cycle and the biological cycle. Whereas technical materials aim to be perpetually used in cycles without any quality loss, biological materials aim to be returned back to the biosphere as nutrition for soil and organisms (McDonough and Braungart, 2002).

In recent years, circular economy is increasingly becoming a debated topic in the field of strategic management. Several contributions have pointed out to the research stream of circular business models, which investigates the managerial practices that companies need to implement for value creation, delivery, and capture (Lewandowski, 2016; Rizos et al., 2016). In this case, the company (such as its organizational structure, processes, and partnerships) represents the main unit of analysis, and the managerial practices it adopts to create and capture value in its circular business model indicate the main points of attention for scholars and practitioners (Merli et al., 2018). In particular, several studies have highlighted two main dimensions of the business model that companies can leverage to implement circular economy principles (e.g., Urbinati et al., 2017). On one hand, the value network dimension concerns value creation by managing the supply chain and its key relationships with suppliers, manufacturers, and retailers (Goldsworthy, 2013; Parkinson and Thompson, 2003; Vermeulen, 2015). On the other hand, the customer value proposition and interface dimension concerns capturing value by managing relationships with clients, reinforced by new mechanisms of value transferring, such as pay-as-a-service (Tukker, 2013; Williams, 2007). In particular, circular business models are addressed as a strategy for sustainable business models. Geissdoerfer et al., (2018a, 2018b) posit that by proactively managing the larger network of stakeholders with long-term perspective, circular business models create additional monetary and non-monetary value. Consequently, the foundational premise of circular economy is integrated to the business model dimensions of value creation and capture. In other words, circular business models refer to an operationalized version of circular economy within the breadth of organizations' business model (Ünal and Shao, 2018).

To create our theoretical framework, we mostly leverage and refine the Urbinati et al.'s (2017) and Ünal et al.'s (2018) previous works by adopting their proposed managerial practices as part of the value network dimension of the circular business model. In particular, these taxonomies emphasize the Design for X practices, such as Design for Recycling (DfR), Design for Remanufacturing, and Reuse (DfRe), Design for Disassembly (DfD), and Design for Environment (DfE). They also underline the importance of the roles of the key partners of the supply chain and the role of the managerial commitment (Kiesler, 1971; Salancik, 1977) to enable the transition towards a circular business model.

\subsection{Conceptual development}

In this section, we briefly discuss the core concepts from business model literature and the business model ontology we have used to build our research protocol and the theoretical framework.

Bouwman et al. (2018) have categorized the business model research into three categories. The first category focuses on the use of Internet and IT for business activities and the level of application. The second category is about innovation and technology management. The 
third category concerns value creation involving the strategic issues regarding firm performance, and this is more aligned with the purposes of this study.

Business model is an analytical concept or tool (Tongur and Engwall, 2014) that explicates how an organization proposes, creates, delivers and captures value (Osterwalder and Pigneur, 2010). Also, the concept of business model has been interpreted as a cognitive schema (e.g., managerial mental model) that reflects the simplified version of organizational reality (Martins et al., 2015), and an "activity system" design (Zott and Amit, 2010). Business model has been studied under different ontologies (i.e., Visor, Stof, Cube, Canvas) (Bouwman et al., 2008). The different ontologies converge on the market offerings and resources whereas there is a divergence on the views of strategy, revenues and procurement (Wirtz et al, 2016). In particular, the Business Model Visor is depicted as how a firm responds to the needs of the customer. The framework stands for the value, interface, service platforms, organizing model, and revenues/costs. The Business Model Stof is more service oriented and based on the interrelated domains such as service, technology, organization and finance (Bouwman et al., 2008). The Business Model Cube is suggested as a generic framework for any business model that is comprised of seven dimensions namely; value proposition, value formula, value chain, network, competences, relations and user \& customer (Lindgren and Rasmussen, 2013). Finally, The Business Model Canvas is a managerial tool that helps better express the business logic and widely used by academic research (Bocken et al., 2018; Fritscher and Pigneur, 2010). It has nine building blocks: key activities, key partnerships, key resources, value proposition, customer relationships, channels, customer segment, cost structure and revenue streams (Osterwalder and Pigneur, 2010). These nine building blocks aggregate under three main dimensions: value network (i.e., key activities, key partnerships, key resources), customer value proposition and interface (i.e., value proposition, customer relationships, channels, customer segment), and economic model (i.e., cost structure and revenue streams).

As the current literature suffers from the ambiguity or absence of a clear business model definition used in empirical papers (Bouwman et al., 2018), we provide here a clear definition and components of the business model we used in our study. This research mainly leverages the ontology of Osterwalder and Pigneur, (2010), the so called Business Model Canvas, to identify main dimensions of business model. The rationale behind this choice mainly derives from previous works (Ünal et al., 2018; Urbinati et al., 2017), which leverage Business Model Canvas due to the its convenience, explanatory power and fit within circular economy paradigm. It has been also recognized by many business model for sustainability studies (Bocken et al., 2018) to give detailed analysis of the integration of sustainable development goals to the business model. In particular, key activities concern the essential operations of business for reaching the success. Key partnerships relate to the any entity, especially the suppliers who helps company create value. Key resources outline the indispensable tangible and intangible assets for business model. Value proposition corresponds to the product or service offered for customers by satisfying their needs. Customer relationships describe the type of interaction the company establish with the customer. Channels reveals the touch-points for value delivery to the customer. Customer segments specify for whom the value is created for, in other words the audience of your value proposition. Cost structure summarizes the cost incurred as a result of orchestration of resources, activities, and partners etc. to propose, create and deliver value for customer. Lastly, the revenue streams associate to the pricing mechanisms that allow company to generate revenues.

In particular, the value proposition relates to the foundations of business model as it indicates the firm's offer to the customer (e.g., stakeholders in systems level) for fulling their 
need. Value creation depicts the process of deploying key partners, channels, resources and practices to form the product (or the service) for stakeholders. Value capture refers to the profit formula of value proposition while benefiting the all stakeholders. Table 1 depicts the main dimensions of Business Model Canvas framework.

Table 1. The ontology followed in the paper (adopted from Osterwalder and Pigneur, (2010)).

\begin{tabular}{|ll|l|}
\hline \multicolumn{1}{|c|}{ Value Network } & \multicolumn{1}{l|}{ Customer Value Proposition and Interface } \\
\hline - Key partners & - & Customer segments \\
- Key resources and capabilities & - & Customer relationships \\
& - & Distribution channels \\
\hline & - & Value proposition \\
\hline - Cost structure & Economic Model \\
\hline
\end{tabular}

The value network dimension depicts the extent to which a company leverages its key resources, activities, and upstream partners to enhance the circularity of its products and processes. The dimension of customer value proposition and interface determines the positioning of the company into the market by identifying the target customers and the type of relationship the company has built with them, as well as the products or services offered (also named value proposition) and the distribution channels. Drivers of this dimension are surely the price, intended as the different modes of offering value to the customer, and promotion, which means the extent to which a company makes its compliance with circular economy visible to the stakeholders (Heerde et al., 2013). The managerial practices at value network dimension affect the costs structure of the company, while those belonging to the customer value proposition and interface dimension enhance the streams of revenues, hence the capability of the company to capture value from its business model. Cost structure and revenue streams constitute the economic model dimension of the business model.

The value creation is one of the core and perhaps most important dimensions of a company's business model that requires specific and in-depth attention (Zott and Amit, 2010). Therefore, we limited to focus of this study to only the managerial practices for value creation within the value network dimension for the sake of providing a clear and comprehensive understanding of the phenomenon in question.

According to Österwalder, (2004) "Activities are at the heart of what a business does" (p.84). Activity is described as "the engagement of human, physical and/or capital resources of any party to the business model (e.g., the focal firm, end customers, vendors) to serve a specific purpose toward the fulfilment of the overall objective" (Zott and Amit, 2010). The terms activities and practices have been used interchangeably by pervious research. As such, Bouwman et al. (2018) asserts "Business model practices involves the way the strategy of the company is expressed in its business model and the way that strategy is implemented". Therefore, the authors depicted the business model practices as transition from strategy to business model in practice. Moreover, Porter and Kramer, (2011) also used the term "operating practices" to described their own view of value creation within the conscious capitalism. As there was a consensus on literature that business models are at managerial level and its managers job to 
design/shape/implement those practices (Zott and Amit, 2010), we stress this aspect by making reference in the paper to managerial practices, as those activities or practices that previous research (Bouwman et al., 2018) addresses to the way top management, usually in charge of defining and modifying over time the strategy of the company, makes the transition to a new business model, a circular one per our case. This approach is also in line with that of Martins et al. (2015), who conceptualize the business models as managerial mental schema (e.g., patterns of thought or behaviour/actions). Accordingly, managerial practices constitute the core of business model by providing certain procedures (a set of actions) to accomplish a task or the goal of the firm. As Bouwman et al., (2018) addresses it as business model practice by defining it as "the way the team in charge of the experimenting process makes the transition from strategy to business models in practice" (pp.105-106).

\subsection{Research Protocol}

We have extensively studied the managerial practices for value creation in circular business models in previous research (see, e.g., Ünal et al., 2018; Urbinati et al., 2017), which puts the attention on the role of business model in the context of circular economy. Therefore, in this section, we first provide an understanding of the managerial practices for value creation in circular business models. Then, in order to enrich the contribution of our research, we pursued to extend our research further by considering a sample of contextual factors that might be influential in the implementation of those practices and are relevant to shape a circular business model of a firm.

\subsubsection{Managerial Practices}

- Energy efficiency-driven practices to reduce emissions and environmental footprint have been of interest of both academia and practitioners as they have implications for business and theory. As such, energy-related issues including renewable energy or energy efficiency have been operationalized by the companies within the scope of their involvement in circular economy to contribute to sustainable development goals. On the other hand, numerous researches studied energy-efficiency and renewable energy to understand the transition and implementation as well as to develop metrics that help better achieve the intended goals of circular economy (Karakaya et al., 2015). Yet, the aim of these practices is to reduce the energy consumption by also relying on renewable sources, such as solar, wind, geothermal and biomass power (Li et al., 2010; Parkinson and Thompson, 2003);

- Environmental-friendly material usage-driven practices are essential for circular economy as the physical products that manufacturing industry produces are constrained by the limited stock that the earth has. This means the material flow of the product, either technical (that is aimed to be perpetually used) or biological (that ends up in soil to enrich ecosystem) is to be considered at the early phases of product design (McDonough and Braungart, 2002; Zhu et al., 2010);

- DfX practices have been considered as catalyst for transition to circular business models (De los Rios and Charnley, 2017; Moreno et al., 2016). The role of design practices (such as design for recycling, design for remanufacturing and reuse, design for disassembly, and 
design for the environment) have been widely acknowledged as companies leverage these practices to enhance the circularity of their products and processes (Goldsworthy, 2013; Mayyas et al., 2012);

- Support of all partners to develop awareness and new skills is a pre-requisite for a viable circular business model, as products and processes, as well as the logic of doing business, are changing radically compared to business as usual. The skillsets and competencies for a circular economy are not yet developed maturely. Accordingly, experimentation and involvement of all stakeholders are essential for reaching the goals of circular economy (Bocken et al., 2018; Moreno et al., 2016; Singh and Ordoñez, 2016). This is also necessary to render business model more viable (in terms of the financial implications of circular business model). As Haaker et al. (2017) underlined, the ability to remain viable and feasible (the extent to which the business model can be actually implemented) create a robust business model;

- Establishment of effective communication with stakeholders is essential due to the fact that circular economy as a part of systems theory inherently requires acting for a common goal with the all value chain actors to realize the transition. Therefore the nature of relationship between suppliers, retailers, and end-of-life materials managers (such as the waste industry), as well as with all actors involved in the supply chain is critical (Geissdoerfer et al., 2018a, 2018b; Lapko et al., 2018; Vermeulen, 2015);

- Managerial commitment is also considered as pre-requisite for a successful uptake of circular business model (Ünal et al., 2018). It is due to the fact the level of resistance against the environmental innovation or change projects are considerably higher compared to that of other types of innovation projects that have profitability at core (Ramus and Steger, 2000). Consequently, the commitment of top management level is critical to align resources with the organizational goals. Foss and Saebi, (2018) also recognize the significance of the management action or leadership on the success of business model innovation by overcoming the context specific challenges. Managerial commitment is defined as the mental state of an individual that determines the interaction (attitudes and behaviours) with the company dimension/s in question and whether to sustain the membership to it or not (Lämsä and Savolainen, 2000; Meyer et al., 2002; Ünal et al., 2018). Reichers, (1985) notes that when individuals are involved in irrevocable, volitional and explicit behaviours, they attribute an attitude of commitment to themselves. Accordingly, this process is binding individuals to their behaviours, which strengthens over time. Research relates the managerial commitment to leadership as it creates foundations for commitment and might consolidate it (Mowday et al., 1983). D'Amato and Roome (2009) underline that "Leadership practices are geared to develop a consistent vision for sustainable development" (p.429). Leadership characteristics, such as strategic sensitivity, leadership unity, and resource flexibility (or fluidity) (Doz and Kosonen, 2008; Massa and Tucci, 2013, p.428; Schneider and Spieth, 2013) are usually understood as meta-capabilities developed by a leader for successful design or reconfiguration of a business model. These meta-capabilities can support management in effectively pursuing the organizational change process toward an innovated business model. In particular, Doz \& Kosonen (2008) define strategic sensitivity as "the sharpness of perception and the intensity of awareness and attention", resource fluidity as "the internal capability to reconfigure business systems and redeploy resources rapidly", and leadership unity as "the ability of the top team to make bold decisions fast, without getting bogged down in 'win-lose' politics at the top". 
Table 2 below summarizes the managerial practices for value creation in a circular business model.

Table 2. Managerial practices characterizing the value network dimension of a circular business model (adapted from the taxonomies of Urbinati et. al., 2017 and Ünal et. al., 2018).

\begin{tabular}{|c|c|}
\hline Managerial Practices & References \\
\hline $\begin{array}{c}\text { Energy efficiency-driven practices to reduce emissions and } \\
\text { environmental footprint }\end{array}$ & $\begin{array}{l}\text { (Li et al., 2010; Parkinson and Thompson, } \\
\text { 2003) }\end{array}$ \\
\hline $\begin{array}{l}\text { Environmental-friendly material usage-driven practices, such as } \\
\text { natural, recyclable, durable, and easy to separate }\end{array}$ & $\begin{array}{l}\text { (McDonough and Braungart, 2002; Zhu et al., } \\
\text { 2010) }\end{array}$ \\
\hline $\begin{array}{l}\text { DfX Practices (such as design for recycling, design for } \\
\text { remanufacturing and reuse, design for disassembly, and design } \\
\text { for the environment) }\end{array}$ & $\begin{array}{c}\text { (De los Rios and Charnley, 2017; Go et al., } \\
\text { 2011; Goldsworthy, 2013; Mayyas et al., } \\
\text { 2012) }\end{array}$ \\
\hline $\begin{array}{l}\text { Support of all partners to develop awareness and new skills, } \\
\text { rendering the business model more viable, or circular, for all } \\
\text { actors involved in the supply chain }\end{array}$ & $\begin{array}{l}\text { (Bocken et al., 2018; De los Rios and } \\
\text { Charnley, 2017; Moreno et al., 2016) }\end{array}$ \\
\hline $\begin{array}{l}\text { Establishment of effective communication with suppliers, } \\
\text { retailers, and end-of-life materials managers (such as the waste } \\
\text { industry), as well as with all actors involved in the supply chain }\end{array}$ & $\begin{array}{c}\text { (Geissdoerfer et al., 2018a, 2018b; Lapko et } \\
\text { al., 2018; Zhu et al., 2011) }\end{array}$ \\
\hline Managerial Commitment & $\begin{array}{c}\text { (Doz and Kosonen, 2008; Kiesler, 1971; } \\
\text { Salancik, 1977) }\end{array}$ \\
\hline
\end{tabular}

\subsubsection{Contextual factors}

In continuous evolving scenarios, business models must innovate their main dimensions to respond to environmental changes and new demand (Hueske et al., 2015; Morris et al., 2005). Therefore, business model innovation requires considering internal and external contextual factors both of which have applicability in the circular economy domain.

\section{Internal contextual factors}

Accordingly, companies can internally exploit strategic orientation (Miles et al., 1978), idiosyncratic industrial capabilities and learning mechanisms (Foss and Saebi, 2017, p.206) to change their business model. In particular, Teece (2017, p.4) describes industrial capabilities as those capabilities "able to continuously sense and seize opportunities, and to periodically transform aspects of the organization and culture so as to be able to proactively reposition to address yet newer threats and opportunities as they arise". Learning mechanisms (and, indirectly, training mechanisms) represent all actions required to transfer the expertise to the organizational members and guide them along the process of organizational change. As Foss \& Saebi (2017) note, the stream of research that relates business-model innovation to organizational change process emphasizes the necessity of leadership, capabilities, and learning mechanisms for successful business model innovation. Strategic orientation relates to the question "What strategies do organizations employ in solving their entrepreneurial, engineering and administrative problem?". Miles et al. (1978) suggested that there are essentially three strategic types of organizations which are Defenders, Prospectors and Analysers. Another type called the reactor is suggested as fourth type of organization that associates to strategic failure due to the 
inconsistencies among the technology, structure and the process of the companies. Based on the seminal work of Miles et al. (1978), the organizational types are depicted as follows: Defenders focus on limited market domain by aiming to protect their market share. Stability is the main goal of this type of companies. Stability is achieved by preventing competitors to enter their market with the actions of high quality products and competitive pricing. By focusing on their niche, Defenders tend to be ignorant to the trends and recent development in the market For Prospectors, the profitability can be compromised at the expense of the innovation and exploiting new opportunities. The rationale of the Prospectors contradicts with the business as usual practices, as managers of Prospectors constantly seeks for new ways of doing business considering the environmental changes. Analysers position between the Defenders and Prospectors by presenting a unique combination of both. The companies fall into this category tend to minimize the risk and maximize the profit by combining the strong features of Defenders and Prospectors. As the balance is sought in this category, Analysers' strategy is one of the hardest to pursue compared to the rest. Furthermore, we consider company age and size as an additional internal contextual factor that may shape the business model. In this way, we take into account Urbinati et al. (2017) comment to critically examine the age and dimension of a company to expand the "discussion on the temporal fashion and on the influence of the exogenous factors in shaping circular business models" (p.496). These internal contextual factors are part of the value network dimension of a circular business model and can reinforce the prominence of Design for X practices in adopting a circular economy and examining the actions conducted by the key partners in the supply chain.

\section{External contextual factors}

Simultaneously, the broad research on business model design or reconfiguration suggests finding consistency between internal configuration and external environmental conditions so a sustainable business model must internally and externally fit (Morris et al., 2005). Morris et al. (2005, p.732) remarked, "Consistency can be described in terms of both internal and external 'fit,' where the former is concerned with a coherent configuration of key activities within the firm and the latter addresses the appropriateness of the configuration given external environmental conditions". Therefore, our theoretical conceptual framework addresses "the appropriateness of the configuration, given external environmental conditions" (Morris, et al., 2005, p.732). It does this by adding external contextual factors that capture industry-, countryand society-level conditions, characterizing the context that can significantly influence the extent to which a circular business model is designed or reconfigured. In particular, by leveraging past research (e.g., Urbinati, et al., 2018), we explore: (i) the influence of geography (local and cultural settings), i.e., the basic values, perceptions, desires and behaviour that a person learns by living in a given country and society (Chesbrough, 1999; Yu and Hang, 2010), (ii) the regulatory framework characterizing the context, i.e., the outcome of the public intervention of an administrative entity, which influences the spontaneous actions and decisions taken by economic actors (Phillips and Scherer, 1971; Scherer and Ross, 1990), and (iii) the level of market competition, i.e., the intensity of rivalry among existing competitors in a given industry (Porter, 1979) - usually driven by the numbers of competitors, industry growth, switching costs, capacity and exit barriers. 


\subsection{Theoretical framework}

We took Klein and Sorra's (1996, p.1056) advice about a call for "integrative models that capture and clarify the multi-determined, multilevel phenomenon of innovation implementation" into account. The proposed framework conceives internal contextual factors and external contextual factors that can significantly influence the extent to which a circular business model is designed or reconfigured. In this way, we propose a two-level framework that integrates the managerial practices for creating value in the value network dimension of a circular business model. Such a model includes internal contextual factors from the most recent research on business model innovation (as a process), and external contextual factors from the broad research on business model design or reconfiguration. The proposed theoretical conceptual framework is shown in Figure 2, and coherently with the research gaps and questions outlined in the Introduction (Figure 1). As it is also acknowledged by previous research in strategic management (Bouwman et al., 2018), we perceived the managerial practices as mediators between context and value creation in circular business models. The fit between internal context and external context has been also considered (Morris et al., 2005).

(1)

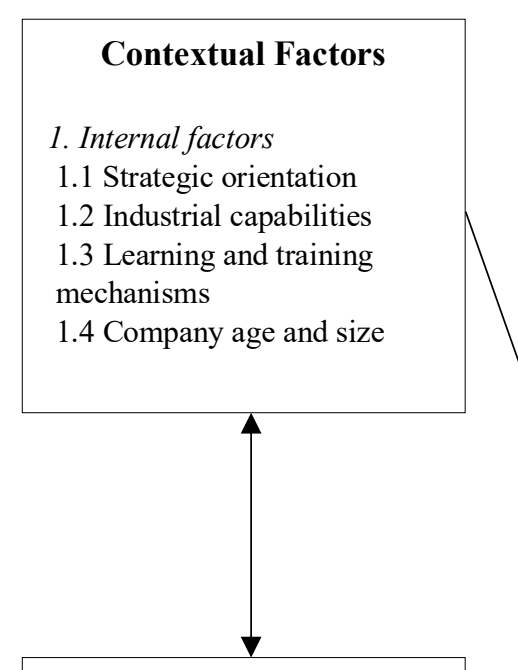

\section{Contextual Factors}

2. External factors

2.1 Geography (local and cultural settings)

2.2 Regulatory framework

2.3 Level of market competition

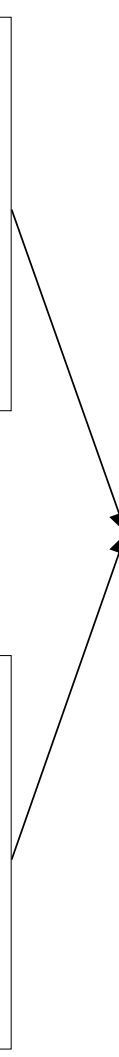

1. Energy efficiency-driven practices to reduce emissions and environmental footprints 2. Friendly material usage-driven practices, such as, natural, recyclable, durable, and easy to separate

3. Design for recycling

4. Design for remanufacturing and reuse

5. Design for disassembly

6. Design for environment

7. Support of all partners to develop awareness and new skills, rendering the business model more viable, or circular, for all actors involved in the supply chain

8. Establishment of effective communication with suppliers, retailers, and end-of-life materials managers (such as the waste industry), as well as with all actors involved in the supply chain 9. Managerial Commitment

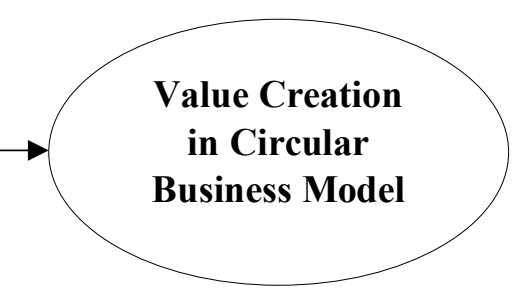

Figure 2. Theoretical Framework.

Previous studies on value creation in circular business models remains relatively vague and mostly insufficient to have a system level approach to present a comprehensive understanding of the interrelatedness and interdependencies. The main weaknesses of previous research originate from the lack of clearly defined variables and the positioning in the business model ontologies. 
The developed theoretical framework spans the boundaries of the firm and informs the value network dimension of firm's circular business model for value creation. The developed theoretical framework is pursed to be consolidated through an exemplary case study in building industry located in US. Given the importance of the built environment for reaching the sustainable development goals, we expect to have stronger contribution compared to the other industrial segments. The case company as a great example of circular economy put into practice might be relevant to manufacturing industry in general as the tools, production techniques and supply chain management would have some commonalities with other industries.

\section{Methodology}

\subsection{Leveraging on a single case study methodology}

This study adopts a single case study methodology (Yin, 2003) to explore the phenomenon in a comprehensive way and test the suitability of the proposed, theoretical, conceptual framework. The rationale of selection of single case study methodology for this study mainly rests on the quality of the cases as "extreme exemplars" that can provide ample learning opportunities (Yin, 1994).

Since the transition to a circular economy is a relatively new phenomenon, we selected a case company that was an early adopter of the circular business model to allow the richness of the observations. This allowed us to consolidate our framework, which incorporated the managerial practices for value creation, as well as the influence of particular internal and external contextual factors. In doing so, we were able to obtain a process view, which the theoretical framework requires. Accordingly, we also used a circular business model's bestpractices case, with a focus on the building sector to maximize insights to be gained from our study. After a detailed review, we agreed on a case company, named Bark House, a SME from the US, which is the first and only Cradle-to-Cradle (C2C) Platinum-certified product holder as of 2017. By analyzing a case from the building sector, we benefit the industry by presenting managerial practices for value-creation processes within a best-practice case that can also be adopted by managers from different industries. The building sector is relatively unexplored in terms of circular business models, despite being one of the biggest resource-consuming sectors, accounting for 40 percent, worldwide (Khasreen et al., 2009). Furthermore, our research purposefully focused on a SME as almost 98 percent of the enterprises in US have fewer than 20 employees, while two-third of employment is generated by SMEs according to the US Trade Representative, 2013. Therefore, SMEs are the backbone of the US economy with a crucial role as the main actors of circular-economy transition. However, the research on circular business models tends to focus on large companies, which calls for a further theoretical and empirical effort to conduct research on SMEs.

To conduct the empirical analysis, an interview protocol, with a structure based on the research protocol and the theoretical conceptual framework (see Table 1A of the Appendix), was drafted prior to the interviews. Semi-structured interviews have been used to allow the serendipity of further events that could be useful for our analysis. The data sources were mainly semi-structured interviews (eight interviews with five interviewees for more than ten hours), the company website, and regularly updated company blog posts, magazines featuring Bark House, and documents shared by interviewees, case memos and certifications. Moreover, the company 
co-founder and other key respondents were contacted frequently by e-mail for further clarifications during our analysis to verify the reliability of our findings. The last version of this study has also been shared with all interviewees for their further verification and input. In particular, the key respondents are comprised of the Chief Executive Officer (CEO) (co-founder at the same time), the other co-founder (Sustainability Officer), a client (founder of an architecture company), Stakeholder Engagement Manager (C2C Product Innovation Institute), Sustainability and Regenerative Planning Expert (co-founder of LEED green building certification). We had to limit the number of interviewees and interviews considering the realities of the SMEs, characterized by limited resources that can be allocated for such external activities (Bougrain and Haudeville, 2002; Lee et al., 2010; Narula, 2004; Terziovski, 2010)In addition, in order to support the validity of leveraging a limited number of interviewees and interviews for the realities such as SMEs, we found some scientific contributions that - as in our case - justify a limited number of key respondents and interviews to advance scientific research (Morse, 2000, 1998).. Coherently with this, and always considering the actual size of the company under investigation, we think that the number of key respondents involved, and the number of interviews we conducted, was more than sufficient to finally enhance credibility, transferability, dependability, and confirmability of all of the gathered information (Guba et al., 1994). Furthermore, we believe that after conducting our interviews, and supporting and triangulating them with the extensive secondary materials and e-mails, we reached the maturity level - as the additional data begin repeating itself - to analyze in-depth the circular business model of the company and consolidate our theoretical framework. The triangulation was achieved by approaching the same phenomenon with multiple data sources (e.g., 57 magazine articles, 69 blog posts in different websites, 126 blog posts within the company website, 28 video recording of the companies' social media channels, a book on sustainable design co-authored by the Sustainability Officer and entitled "Bark House Style: Sustainable Designs from Nature"). We have created a data archive to systematically review all sources iteratively.

All the interviews have been transcribed and during the coding process, all authors have been involved to strengthen the reliability and validity of the findings. A traditional coding process in content analysis (Weber, 1990) was performed that basically relies on the interpretation of the data analytically (Corbin and Strauss, 1990; Glaser and Strauss, 1967). In particular, axial coding process is undertaken in which the categories that are constructed by subcategories and the possible relationships between them are tested against the data (Corbin and Strauss, 1990). In particular, Corbin and Strauss (1990) have defined axial coding as "a set of procedures whereby data are put back together in new ways after open coding, by making connections between categories. This is done by using a coding paradigm involving conditions, context, action/interactional strategies, and consequences" (p.96). Thus, we focused on the conditions that gave rise to a category or phenomenon (value creation in circular economy business model), the context or specific set of properties (a sample of relevant internal and external contextual factors) in which this category or phenomenon is embedded, the actions or interactional strategies (the managerial practices for value creation in circular business models) by which the implementation of circular economy at business model level is carried out, and the consequences of the strategies (Kendall, 1999). Accordingly, our theoretical framework provided us a clear road-map on processing the coding and transferring the results to the final Figure 3. in which the theoretical framework is consolidated through empirics. 
Then, triangulation of information collected from primary and secondary sources rigorously followed the steps suggested by Tellis, (1997): initially, each author independently reviewed all the information of the transcribed interviews and secondary documents to verify their validity and avoid potential ambiguous and equivocal data to be included in the database. Then, each author contrasted or corroborated his own analyses with the ones of other authors to reach a shared understanding and interpretation of the whole information under investigation. Finally, the authors triangulated all the accepted information. Anytime, we looked into our framework to create conceptual labels, categories and sub-categories.

\subsection{Brief introduction of the case and analysis}

Bark House is a SME, founded in 1990 by a wife and a husband. It is located in the Appalachian region of the eastern United States, with 30 full-time employees. It operates in the building materials industry, and its main product is bark shingle made of waste wood that is called RAWW (Recycled Appalachian Wood Waste). The product is used as exterior and interior wall coverings in built environments, as well as for many other decorative purposes.

The husband keeps the position of the CEO (as well as co-founder) and the wife occupies the position of Sustainability Officer and co-founder even if she claims their positions and roles are changing time to time based on the situations: "I am co-founder and co-owner, but my titles mutate according to role and function". The co-founder of the company has a health care background, so she depicted it as analogous to the building industry. The holistic approach to health care is fundamental, from the perspective of how parts of a human body are treated by considering the integration of body, mind, and spirit. By referring to the Polish physician Kazimierz Dabrowski, she underlined the model of human development as actually circular: "Every human system built on a linear fashion will fail, it should, because linear is not the way of life". She transferred those premises to her business by emphasizing: "I contemplated that being holistic was important when we were talking about other systems, business systems, processes, and especially when it comes to home". In addition, the co-founder subscribed to the view of theorist John Ruskin, who introduced the concept of material honesty - truth in material - doctrine, as one of the main principals of architecture. She explained: "Truth in materials, so showing the material for what it is and bringing it forward in that light and not trying to make it be something that it is not". Detailed information about the case company is summarized in Table 2. 
Table 2. Case Company Information.

\begin{tabular}{|l|l|}
\hline Company & Bark House (https://barkhouse.com/ ) \\
\hline Country & USA \\
\hline $\begin{array}{l}\text { Interviewee, number of interviews } \\
\text { and duration }\end{array}$ & CEO (Co-founder) (one interview, more than 1,5 hours) \\
& Co-founder (Sustainability Officer) (four interviews, more than 5 hours) \\
Client (Founder of an Architecture office) (one interview, more than 1,5 hours) & Sustainability and Regenerative Planning Expert (Co-founder of LEED Green \\
& Building Certification and author) (one interview, more than 1,5 hours) \\
& C2C Certification Stakeholder Engagement Manager (Cradle to Cradle Product \\
& Innovation Institute) (one interview, more than 1,5 hours) \\
\hline Secondary material & $\begin{array}{l}\text { Company website, Company blog, Certifications, audio-videos, } \\
57 \text { magazine articles, 69 blog posts in different websites, 126 blog posts within } \\
\text { the company website, 28 video recording of the companies' social media }\end{array}$ \\
\hline channels, a book on sustainable design co-authored by the Sustainability Officer \\
(entitled "Bark House Style: Sustainable Designs from Nature")
\end{tabular}

The other/external key respondents have diverse background and profiles that enabled us to gain prolific insights. The client is the founder of an architecture company (in 2004) and collaborated with Bark House in one of its projects by using the waste bark as interior wall covering of a university hall in New York. The client thinks that taking care of existing structures instead of building new ones saves a lot of energy and resources. Accordingly, he mentions that his company that collaborates with Bark House is also aligned with the premises of circular economy in the form of re-use: "We are passionate in our practice's focus on the adaptation of existing buildings for re-use rather than tearing down and rebuilding". Sustainability and Regenerative Planning Expert (henceforth "the sustainability expert") is the co-founder of green building initiatives and LEED certification. At the same time, he is an author on regenerative development and his interaction with the co-founder of Bark House was through a professional circle on activities and teaching on regenerative business. Lastly, the $\mathrm{C} 2 \mathrm{C}$ Certification Stakeholder Engagement Manager (henceforth "the C2C manager") works in the C2C Product Innovations Institute and helps manufacturers to adopt the principles of $\mathrm{C} 2 \mathrm{C}$ as one of the schools of thought of circular economy. She has socially responsible business and sustainable business background. In addition, she is in charge of organizing webinars with the co-founder of Bark House to tell the story of the best practices for sustainable initiatives. The $\mathrm{C} 2 \mathrm{C}$ manager indicates that "Cradle-to-Cradle makes circular economy a viable proposition. It provides a pathway to make safe and circular products". For the sake of the clarity and considering it is a family company, henceforth we will call the husband as CEO (even if he is also the co-founder) and the wife as only co-founder for a clear distinction. 


\section{Results}

This section illustrates the analysis of the data based on the suggested framework that consists of our theoretical guide to analyse: (i) how contextual factors influence the extent to which value is created in a circular business model, as well as (ii) the managerial practices that are implemented by companies in the value network dimension of their circular business model for value creation and how these practices mediate the influence of the contextual factors on value creation.

\subsection{Contextual Factors}

In this section, the particular internal and external contextual factors that influence value creation in circular business models are analyzed through the case.

\subsubsection{Internal Contextual Factors}

In terms of strategic orientation, the company has been found out to be a Prospector as the company is mainly driven by exploiting an opportunity that nature provides (valorizing a natural waste) and sustainability-oriented innovation rather than profitability, as the co-founder says: "It's just a part of doing business, and it's not something that you look at as a cost. I mean, what's the cost of not doing that? That's my question, that's the bigger question". As such, the company reported that most of the time, it contradicts with the business as usual logic: "We do not make decisions that are... I mean, they are not always 100\% smart business decisions. Sometimes, they are for the good of the community, (but) they are not for the good of the business" (says again the co-founder). Furthermore, the CEO adds that they are not following the business as usual approach, but rather challenging it together with the co-founder: "We always listen her (the co-founder's) capacity to understand what is best for people, and what is best for people is not extractive but regenerative". The idea of both the CEO and the co-founder is to focus on the qualities that bind us instead of separating us. From the client's perspective, he thinks that the company was successful in terms of creating novelty and accordingly having the business success: "I know that they (Bark House team) are progressive people and it doesn't surprise me that a more people want to work with them". The client underlines the novel characteristic of Bark House product: "Something traditional can become something innovative". Moreover, as the company is considered a great example of circular economy put into practice, the $\mathrm{C} 2 \mathrm{C}$ manager explains the motives of the companies in general who are embarking in circular economy and $\mathrm{C} 2 \mathrm{C}$ journey, which is in line with the Prospectors' approach: "There are some companies that really see it as an opportunity to demonstrate their leadership either in sustainability or thinking ahead of the curve".

By analyzing the industrial capabilities, they cannot be restricted solely into routines as some of them are unlikely to be routinized, such as dynamic managerial capabilities, which have also been studied as a sub-field of dynamic capabilities. Consequently, dynamic managerial capabilities are shaped by the managerial competence that stems from the managers' backgrounds, including education, personal traits, and culture. Managerial competences are the key element of a firm's dynamic capabilities that help devise and refine business models. The cofounder was mostly responsible for the strategic decisions. She also was an entrepreneur with a health-care education background. The CEO (the co-founder's husband) has a background in 
chemical engineering and architecture. The co-founder explained that when they started their own company: "He wanted the products to be pure and I wanted the processes to be holistic so, we combined that in our contemplation and our drive to really have the foundation of the company reflect those two attributes. We traced what we wanted to do back to a real honest material which was bark, bark from a tree, bark that was being wasted, something that other people did not see value in, but we thought it's beautiful and having value". The co-founder acknowledged the significance of the biomimicry approach on their business development by asserting: "Nature gave us all the examples that we needed to understand those patterns". Dynamic capabilities enable the business model which requires sensing the opportunities at the first place. The co-founder reminds that in the 1990s, there was a large building boom in the Appalachian region, and she was concerned that people were losing their connectivity with nature: "We are so separated from nature and we are spending more than 90\% of our time inside buildings. It is largely, it is very important to get nature back into the built environment". Both the CEO and the co-founder started their business as a reaction to this: "So it really started off as a way of contemplating, connecting people to nature in this place. We wanted to remind people all of the reasons why they were coming to this area and we wanted to help them to very definitively attach to nature". Using the bark as an exterior cladding, and then for interior walls, seemed to be a way to let people to reconnect with the nature and beauty of the Appalachia Mountains. Further, the $\mathrm{C} 2 \mathrm{C}$ manager summarizes how Bark Hose grasps the opportunity of leveraging the waste: "They taught people working in timber industry that they can actually make more money from the waste material than they could from the timber itself". Apart from creating a sustainable product, the co-founder asked other questions on various aspects about starting the company this way: "What impact have we had on our community? What impact have we had on our customers? What impact have we had on the lives of our employees, our vendors, what impact do we have in the environment? What impact have we had on the economy? And these are really the questions that we are asking ourselves. These are the important questions". Both the CEO and the co-founder spent five years on Resource and Development (R\&D) to create a building material that was "pure and whole". The company's bark shingle product had not been created before in mass for modern, airtight construction, so, the company needed to innovate: "So, new methods had to be engineered for its manufacturing. Tools, equipment, supply chain, clients; all had to be created" (Source: Company blog). Accordingly, we observed the company's supplier-integration capabilities that have a critical role for the successful execution of a circular business model in our case. By actively managing the suppliers, the company increased its process flexibility and market performance. The co-founder underlined the novelty of their product and process by explaining: "When you are looking at technology and you are looking at a process that did not exist before we created the manufacturing processes for the bark shingles". She indicated that they created the customized machinery and dry-kiln process from scratch: "There was never any dry kiln built for the drying of bark before this". In similar vein, the CEO emphasizes: "There is absolutely no component out there that associates with our business", and also "the need for experimentation and manipulation on material until a process is discovered that allows it to be economically viable". After building the technology and process for the new material made of waste, the company asked the Safety and Health Achievement Recognition Program to audit them because they wanted to ensure their process is safe. As the co-founder noted, the company had received the highest level of award that a company of their size could obtain. Moreover, the company holds the world's first and only C2C Platinum certified product as of 2017 , which would be the highest level compared to 8,000 
products from 260 companies certified. This can be interpreted as a competence that could not easy be replicated by competitors and might stem from the company's dynamic capabilities.

Once we analyzed the learning and training mechanisms that the company employed, the expertise was transferred by active supervision and coaching to let employees enliven their strengths, and even go beyond it by establishing their own businesses. It was a reciprocal interaction process as the co-founder puts it: "We get employees to decide for themselves (as the employee says: 'My job would be better with this'). That improves the company, and that tiny example is translated into everything". The CEO posits that the training allows all employee to know any tiny detail of entire the business process: "Everybody here run through every single process. [...] They (the employees) are cross-trained". The sustainability manager asserts the importance of social enhancement: "She (the co-founder) is building the capacity and capability into the people to carry on the co-evolutionary relationships in the future".

Regarding company age and size, these factors were influential as a part of value creation. For instance, history-driven factors, such as the trust and supplier base, community improvement, customers and the reputation gained over time, may be leveraged to create value. The size of a relatively small company indicates the circumstances of undertaking multiple roles, as the co-founder reports: "Nobody is going to sit back on their laurels. We are too small for that. We all wear multiple hats, but at the same time, you know, each employee knows better than anyone else how to do his or her job, and we anticipate them improving their job constantly". Being a small company allows them to be entrepreneurial, and "not driven by profit but driven by balance", which is the core of the company's regenerative, circular business model. She indicated that being a socially responsible, regenerative SME resembles "being in a Mini Cooper in a highway with a bunch of tractor trailers". Moreover, they have fewer resources than larger companies, especially in terms of human capital. The co-founder used the process of organizing for certifications as an example of this: "The management of the data points, the tracking of the data, holding the data and keeping that together is quite cumbersome on the internal staff, in particular because we are a small company". The $\mathrm{C} 2 \mathrm{C}$ manager also emphasizes that Bark House constitutes a great example in terms of its big achievements although its small size.

\subsubsection{External Contextual Factors}

Previous research defines geography as differentiation of continents (East versus West) and countries, in terms of how circular economy is implemented. However, we recognize that this approach might be too oversimplified to be adopted within the context of circular business models. For instance, there are stark differences between Europe and the US, regarding their approaches to circular economies, despite the fact that both continents are generally geographically considered the West. To illustrate, the EU is playing a proactive role by creating action plans for circular economies and incentivizing businesses to adopt circular economies. It is also doing business with companies that adopt circular economy. This also concerns the regulatory framework part of our theoretical model (Figure 2), as the practices are interdependent. In many EU member states, the circular public procurement plays a major role as a driver for circular-economy transition. Equally important, there may even be differences at the regional level within the same country, as business, policy, societal and environmental dynamics would be specific to particular locations. Therefore, our definition of geography concerns the inhabitant-environment interaction in an area with distinct and interdependent cultural, 
biological, and physical features. The view of the sustainability expert on the role of geography is more in line with our definition as he asserts: "We always start with geography, you cannot change mother nature. [...] It (geography) also changes culture”. In line with this approach, there are not a lot of economic and job opportunities in the company's Appalachian region. The co-founder explains that shared prosperity is important for local inhabitants: "We actually put $70 \%$ of the income from the company straight directly back into this community. So that's better than a lot of not-for-profit charitable organizations". As part of their circular and regenerative business, the company is increasing the income of the Appalachian region and focusing on small, independent business owners by growing that vendor base and nurturing some employees to move into their own business ownerships. As mentioned previously, the regional culture is distrustful, yet trust is fundamental for doing business in the region. The independent nature of the people in the region obliged company to adapt itself based on the location and cultural settings. As such, management and business-model literature consider contracts to be crucial for supply chain collaborations. On the contrary, our case shows that supply chain collaboration is context-specific, which might be determined by geography. Accordingly, the suppliers for the case company are not contracted. This practice may be influenced by location and culture. In addition, geography is one of the critical aspects of the circular business model, especially those focusing on closing the resource loop, which determines the characteristics of the waste to be recycled. The local natural waste, as a part of the geography, also creates one of the fundamental aspects of circular business models. Therefore, the physical features of the location may indicate which kind of businesses would be located in a particular area and which type of waste they produce. As seen in the case, the company shaped its business based on the region's socioeconomic settings, which are mostly based in the forest industry. Accordingly, the company recycled logging waste, with logging companies as its suppliers. This indicates a high level of dependence between the company and these stakeholders. In particular, the waste material generated by the loggers becomes part of the company's production of goods or materials for specific purposes. Therefore, procuring the waste depends upon which products the suppliers are making. The company also states that no single tree has been cut down to get the waste material (tree bark). This condition creates a potential burden for companies with circular business models that are based on recycling or upcycling. Such companies highly depend on their waste suppliers' production plans, which may vary, not be clear and reliable, or not be accessible. Therefore, recycling the waste might generally indicate a certain level of vulnerability for certain industries. However, by growing its number of suppliers, the case company reduced the risk of raw-material shortages that might cause disruptions in production.

Regulatory framework significantly influences the anatomy of innovative phenomena, so it is crucial to understand how companies encompass the circular economy in their business model. Having analyzed the inter-connected section of geography, we can say that the legislative infrastructure and regulatory framework is more developed in the EU than in the US to favor circular businesses that might affect the value creation process. In line with this, the case company has not been prompted by legislation. Similarly, the company has not benefited from any public-procurement incentive. In particular, the company has an idiosyncratic advantage, as the process and the product are simple and natural, and stem from leveraging biomimicry. Therefore, the firm is not restricted by the hazardous and toxicity regulatory framework. Yet, the company goes beyond environmental regulations, in terms of having the best Cradle-to-Cradle practice. The company also collaborates with customers once they come up with an idea. Some examples of these collaborations include customizing the product, improving its specifications, 
and using it for different applications. The co-founder mentioned that the company worked with the architects to increase the product's noncombustible properties, as the exterior wood applications are not allowed by regulations for industrial buildings. Therefore, the company leveraged external resources to overcome regulatory barriers. In addition, the company does not benefit from any incentives regarding the circular economy. Current regulations do not protect SMEs, especially those operating with circular business models. The co-founder explained that tax incentives, regulations, and financial support are necessary to protect these types of SMEs.

Accordingly, the level of market competition was an issue for the company as its logo, mantra, and website were closely imitated by another company producing poor quality goods. A contextual, environmental factor, such as market competition, can influence the dynamics of doing business, and innovation is a critical aspect of this (Urbinati et al., 2018). As the cofounder explained, they have handled market competition with the support of the community, workers, and clients over the past several years. The company bases its competition on its process as a source of competitive advantage: "Our commitment, our essence and our stories cannot be duplicated." (Source: Company blog). This includes protecting trade secrets, intellectual property and trademarks, as essential for non-displaceability.

\subsection{Value Network}

The value network dimension has been analyzed in the following sub-sections coherently with the managerial practices proposed in our theoretical conceptual framework.

\subsubsection{Energy efficiency-driven practices to reduce emissions and environmental footprint}

The CEO underlines that they are self-sufficient energy-wise due to the advantages of working with a natural material: "All of our material processing is completely net zero. Our energy consumption is going to be limited to vastly less than any other building material because our material is organic in shape and nature". The co-founder stated that the production process used to highly rely on heat, which can be energy ineffective. Therefore, the company acted to maximize the decrease in energy consumption by improving the process, advancing insulation, and using $100 \%$ solar energy on site to assist with energy utilization. She said these investments were part of doing the business rather than a cost or burden. The use of renewable energy is certified through the Cradle-to-Cradle Product Innovation Institute and realized as a requirement from the certification as a part of the circular economy.

\subsubsection{Friendly material usage-driven practices (natural, recyclable, durable, easy to separate)}

The co-founder underlines the importance of using natural waste material: "We had some builtin benefits to what we were doing because of the natural products". As the biomimicry approach suggests, the company is exploiting the opportunities that nature provides. The co-founder further emphasized this by asserting, "We recycle the waste material and it is fully biologically recyclable, biodegradable". Compared to other products in the same market, having a biodegradable product that closes the resource loop is an advantage: "I think that that is one of the biggest challenges for other companies, because they are dealing with the chemistry of things". The substitution might impose a higher cost, or it might not even be possible to find a better compound. In line with this, the $\mathrm{C} 2 \mathrm{C}$ manager confirms that the characteristic of the material in terms of the cycle it was intended for after its useful life might determine the 
circularity performance: "It also depends (either it is) technical or biological material. For example, for Bark House, it is potentially easier for them to get to Platinum (the highest certification level) than a technical material". As the client of Bark House reports, he was hesitant to use products that have complex chemical composition as through time our perspective (regarding toxic or non-toxic) on the chemistry of things are changing radically. The client summarizes its requirements for materials as: "We were looking for the enduring, resilient material" and "The less processed materials are for us, the better. When we select woods, we prefer to specify unprocessed woods, rather than wood products". After a detailed inquiry, the client was able to find Bark House and visited the company and their facilities located in North Carolina ten years ago. Today, the client says: "It really could not have been better for us. The durability of the product is self-evident" and adds: "The bark panels were installed 10 years ago, and they look like the day they were installed". The client summarizes his motives to use the company's product as the urge to re-connect to the nature: "We were looking to amplify the primal character of bark, displaced from the forest of the Carolinas, into the urban context of New York City. Even a modest sampling of the forest, of nature, can be incredibly powerful". The $\mathrm{C} 2 \mathrm{C}$ manager underlines the transformation of waste to commercial product: "How valuable waste material could be? Bark House opened up a new conversation locally and they either are a very passionate local player".

\subsubsection{DfX practices for circular business models}

Given that the company's product is a natural, biodegradable product, yet lasts 80 years outdoors and has an unlimited life indoors, the opportunities for remanufacturing and disassembly are not among the possible options. Therefore, in terms of resource conversation, the company designs for closing the resource loops, which indicates a design for biodegradability. This would then require a design of biological and technical cycles. By producing long-lasting products, the company also aims to design for product attachment and trust. From a systems perspective, the company adopts a design for biomimicry, as the solution of nature is used for its original purpose. Having focused on the supply base by procuring 90 percent of the waste within 50 miles, the company aims to design for the local value chain. In addition, by considering slowing resource loops, the company pursues design for recycling/upcycling. The generic design principle that the sustainability manager suggests for a regenerative circular economy is: "We need to use the built environment to heal the environment".

\subsubsection{Support of all partners to develop awareness and new skills, rendering the business model more viable, or circular, for all actors in the supply chain}

As the CEO claims, suddenly the suppliers have become part of Bark House's designers in the sense that they started to bring interesting pieces of wood materials and to ask what if the company tried to create something out of it. The CEO asserts the importance of his suppliers as: "They (our suppliers) help make us who we are". The CEO and co-founder stated that working with suppliers, and training and educating them regarding quality, best-management practices and sustainability are essential, as it is part of suppliers' business: "We train them in the quality variables that we discussed. We train them in sustainability. We train them in best management practices. We relate to them the practices that we want to see implemented." The company claims that it has trained more than 1,000 loggers from 250 suppliers. The company took 
necessary actions to guarantee its successful execution of the circular business model. The cofounder emphasized that relationships with suppliers are on a win-win basis, as their income increased three-fold for each log by selling her the waste bark. The CEO echoed that the company is working with material that does not have any commercial value and stresses: "To me the important part of our innovation is to find usages for the thighs that are generally discarded". The $\mathrm{C} 2 \mathrm{C}$ manager agrees on this point by stating: "A lot of the companies looking at it (C2C and circular economy) as a driver for innovation". In addition, the sustainability expert underlines the importance of evolutionary perspective and continuous improvement in circular economy: "Circular economy is right idea, it just needs to be employed in place with the intention of evolution. [...] How do we use the materials and resources we have to further quality of life?"

\subsubsection{Establishing effective communication with suppliers, retailers, and end-of-life materials managers (such as the waste industry), as well as with all actors involved in the supply chain}

Based on its 27-year history and circular economy implementation as a regenerative business, the co-founder emphasized that the vision of the company was shaped around circular economy and regenerative design. She explained how the company perceives this: "Circular economy helps us to redefine our relationship and our understanding of raw materials and what we consider waste and how to use that". Consequently, the co-founder stressed the significance of effective relationships for the business: "It is the relationship (suppliers, clients, community) that creates a legacy and makes the company non-displaceable in the marketplace” (Source: Company blog). She stated that the goal of the relationship is to contribute to the local region: "Our entire company is built upon relationship. And it is driven to improve and regenerate this area". The co-founder also noted that the company is working with 250 suppliers that provide the raw materials. The company does not purposely contract with suppliers, and its suppliers are fully independent. The cultural background of the suppliers is mostly Native Americans, while some are Amish even if they are disenfranchised from tribal belonging and no one's name would appear on a tribal roster. Since some suppliers do not even have cell phones or internet, the company often pays them a visit. The co-founder explained: "You are respectful with their space and their time. So, it is a very intimate, very personally engaged process". She also indicated that mutual trust is fundamental in interacting and collaborating with suppliers: "Trust is absolutely imperative in this area. And once you lose trust, you are not going to function in business very long here". The co-founder explained how the company works with its suppliers: "So, it becomes a variable of spending time with them, building trust with them, showing them what is possible, and then treating them with the utmost respect so you can build relationships through the years". She also noted that most of the suppliers are barely making life for themselves: "People who live here are independent and prideful, and they do not want to work for the man... but they want to work for themselves. They want to be independent in their work". When they created their business based on transforming a waste material into a valuable product, the co-founder explained the reaction of the suppliers as: "So, you cannot imagine how many times loggers (suppliers) say I used to drive over this stuff, and I cannot believe that I could have made money on it." As their business focuses on developing the Appalachian region, the cofounder explained her experience: "It is really hard to convince loggers (suppliers) that for a waste product in the forestry industry, they can actually receive four times as much pay for that material as they do for the log that is going to a mill". Furthermore, the client notes that the team 
of Bark House is very caring throughout the time he first visited the company till now., even after 10 years of his purchase, the co-founder of the Bark House kept it touch with the client by leveraging purposes of personal communication and not of the business concerns. The $\mathrm{C} 2 \mathrm{C}$ manager also underlines the importance of relationships with suppliers: "You have to have a good relationship with your suppliers. [...] The internal communication, internally with their (top management: CEOs, managers and founders) own company and with their suppliers, is really important. Not seeing it just as transaction, but partnership. Working with the suppliers to explain the value of going through that process (the certification and circular economy implementation)".

\subsubsection{Managerial Commitment or Leadership}

In terms of managerial commitment, the CEO and the co-founder identified themselves with the doctrine of the business and they were willing to sustain the philosophy of the company. The willpower to do their business, making their actions explicit, and 27 years of consistent lines of activities indicate a high level of managerial commitment that also induces organizational and supplier commitment (Reichers, 1985). As the client notes, the personal traits of the CEO and cofounder and Bark House team made a very favorable impression on the client, who sustains their relationship over a long period of time. The CEO summarizes his role and that of the co-founder for Bark House and how they are working together as: "If I am the framework and structure and overall running of the company, she (the co-founder) is a lot more than the soul of it." The CEO also explains the commitment of co-founder as: "She always looked for step by step process of how this company can become larger than a company, how can it just become a life for an area". The CEO also emphasizes their determination on the long-term and consistent path they choose for business: "Certainly we want prosperity and maximize it for us, for our supplier, four our employees, for other folks that used the material, but at the same time not to the point of compromising our core values of who we are". From the view point of the client, he associates the successful realization of circular business model in Bark House to the combination of personal traits and superior product: "They (Bark House team) are really good people. That they have a great product that is sustainable, part of a circular economy, and that it uses a part of trees harvested for other purposes, strengthens the draw to them". Furthermore, the C2C manager stresses that the internalization of circular economy is necessary to get the best out of it: "Companies that embed it (C2C and circular economy) more deeply in the culture will get more benefit out of it than the ones just do it as token product". In addition, the sustainability manager posits that what Bark House is doing is more than a business: "She (the co-founder) is taking it (the business) beyond the manufacturing into the community and eco-system as part of her role and responsibility". In addition, the CEO and co-founder adopt coaching and visionary leadership styles, as they constantly motivate, encourage, and inspire both employees and supply chain partners. By active supervision, both the CEO and co-founders ensure employees and supply chain members to develop their skills and understanding of sustainability requirements. Thus, as far as managerial commitment or leadership is concerned, both the CEO and the cofounders have particular attributes (attitudes and behaviours) that help explaining how they manage the company. Furthermore, both the CEO and the co-founders may have strategic sensitivity capabilities, as they are aware of strategic developments and opportunities such as training employees and suppliers; being coherent and authentic with the company philosophy; and experimenting to develop the product and process in line with the business model. In addition, leadership unity capabilities were present, as both the CEO and the co-founders share a 
common interest with the stakeholders. They also show caring by providing empathy and making explicit aspirations with bold decisions, such as reserving $70 \%$ of the income for giving back to the community as a regenerative business. To illustrate more in detail, the leadership unity can be seen by their approach to the stakeholders, as the co-founder explained: "We are increasing the income in the Appalachian Region, and focusing on small independent business owners, growing that vendor base, nurturing some of our employees to move into their own business ownerships". The company focuses on development of the employees, while at the same time benefitting from continuous improvement: "That is the whole purpose of regeneration and enlivening potential as they continue to define their roles and then to give us feedback on what that role needs to be and how they can do their jobs better". Moreover, the co-founders' leadership helped manage the configuration of resources and capabilities based on circular business model for closing the resource loop. For instance, buying any amount of waste with an instant monetary-transaction policy indicates the company's resource fluidity capability. For the sustainability expert, the goal of circular economy should be to create a regenerative system and Bark House is achieving it to a certain extent: "What makes it (Bark House) regenerative is that the CEO is engaging his staff and community members to understand their role in the system".

\section{Discussion}

The paper adds interesting theoretical implications that we summarize hereafter in terms of a set of propositions that are open for future research in the field of circular business models. In particular, the synthesized results of the case are summarized onto the theoretical framework dimensions in Figure 3.

In this study, we perceive the circular business model as a holistic system of co-evolving managerial practices for collectively creating, delivering, and capturing value that provides solutions to sustainable development. By leveraging a broad set of theories and literatures from different domains that construct our theoretical framework, we show that the value in circular business models is more comprehensive and includes both monetary and non-monetary aspects in a harmony. As Solaimani et al., (2018) stresses: "Implementation becomes more complex when a business model is proposed by or requires a network of collaborating enterprises" (p.79). The value in circular business models is a shared, co-created output that contributes to the wellbeing of people, nature and culture, once it is monetized.

Whereas the materialistic approach to a circular economy that solely focuses on resource use restricts the realization of the essence of the concept, this study's contribution aims to provide a more systematic approach by encompassing the interdependencies between the adaptability of the company, the regeneration of natural waste, and the socially and environmentally regenerative nature of the circular business model that the case company pursues. In particular, the findings indicate that regeneration, in terms of resources and location (regional economy and society) is one of the sources of value creation in a circular business model. As Bark House perceives, the regeneration relates to the extent to which the evolution process of people, institutions and materials can fulfill their inherent potential in constantly changing world. Reed, (2007) suggests regeneration focuses on "evolution of the whole of the system of which we are part" (p.677) and contribution to the value-generating process of living systems (Mang and Reed, 2015). Thus, socio-economic regeneration has been identified as one of the essential sources of value creation in circular business models. 


\section{Propositions}

In addition, business-model literature can benefit from our study, as we showed the role that the circular economy has in companies' strategies to create differential value in partnership with supply chain stakeholders. We also showed the role that particular strategy dimensions have in shaping a circular business model as a process (Foss \& Saebi, 2017, Doz and Kosonen, 2008; Massa and Tucci, 2013, p.428; Schneider and Spieth, 2013). Therefore, the internal and external contextual factors that comprise several intrinsic and extrinsic variables might determine the nature of value creation. The configuration of a circular business model is mainly set up in response to particular contextual factors, which are critical elements of circular economy. Ensuring balance between internal and external forces is essential for creating value in a circular economy domain (Morris et al., 2005). In addition, our research shows a holistic approach for creating value in circular business models by perceiving the resources, capabilities, methods, and context (such as the level of market competition and the regulatory framework) as part of a system with high levels of interdependences and interactions to deliver the value. In particular, by considering contextual environmental factors ex-ante in our study and showing their influence in shaping a circular business model, we advance existing research in this domain, as contextual factors could be generalized to other populations of companies and industries. In addition, Leising et al. (2018) suggested a collaboration tool for circular economy in building sector and underlined that the contract is one of the main elements of process design and collaboration. Yet, we have showed that the nature of collaboration determined by the socio-cultural and socioeconomic context, as it was not possible for Bark House to contract their suppliers.

Proposition 1: Contextual factors, internally and externally fit, determine the nature of value creation in circular business models by characterizing the bundles of managerial practices to be implemented.

Yet, it is important to underline the inherent paradoxes and tensions that the circular business model signals (Linder and Williander, 2017). Recovery and processing of technical materials, especially critical materials that might cause supply disruptions for the high-tech industry and emerging innovations (European Commission, 2018; Lapko et al., 2018; Peck, 2016) may not be viable for business. This might be due to a failure to incorporate the relevant design practices in the early phases of product development (such as DfX practices). In addition, costly capital commitment to enable recovering technical materials might risk the financial survival of the business. Likewise, the process of recovering these materials might even have more embedded environmental and social impact that can have rebound effects (Zink and Geyer, 2017). Ingrao et al. (2016), and Intini and Kühtz, (2011) stated that utilizing waste or by-products to create alternative building materials lead environmental gains and prevents the impact of harmful processes on planet as the company did. On the other hand, the biological materials in the context of circular business models might impose a certain level of risks that can be harmful for the environment, if not mitigated (Reijnders, 2008). As such, the unbalanced return of biological materials to the biosphere may cause excessive nutrient richness that is beyond the environment's absorptive capacity, known as eutrophication (Pomponi and Moncaster, 2017). In addition, companies that use waste as raw material might face the risk of supply disruption, stemming from high levels of supplier dependence. As the waste by-product is a result of the companies operating for different purposes, it cannot be produced to order. Recycling the waste 
highly depends on the suppliers' original production plan, which can vary, not be clear and reliable, or may not be accessible. Therefore, companies that are willing to design a circular business model should be critical and consider the potential unintended outcomes. In parallel with company actions, executing circular business models should be supported with innovation for success (Ghisellini et al., 2014; Küçüksayraç et al., 2015). Still, the intensive R\&D and innovation process as a result of adopting a circular business model may indicate costly investments (Gregson et al., 2015). As such, the high capital commitment might offset the financial viability of the business, as it was the dilemma for the case of technical - critical raw materials (Lapko et al., 2018; Linder and Williander, 2017). Since the circular economy is a dynamic and evolving concept (Merli et al., 2017), such a position might help further develop circular economy science, rather than celebrating it for its own sake.

Proposition 2: Understanding the potentially paradoxical nature of a circular business model and having a critical stance to its premises would help business prosperity for a more balanced transition.

Managerial commitment and accordingly the leadership characteristics (Doz and Kosonen, 2008; Kiesler, 1971; Salancik, 1977) are critical as circular business models require short term monetary compromises for long-term gain. As it might contradict with the premises of business as usual that prioritizes the monetary aspects and creates value only considering the customer, the core foundations of a circular business model should be internalized firstly in focal company and then through the value network for a successful realization.

Proposition 3: Managerial commitment facilitates value creation in circular business models through the internalization of what the business stands for. The alignment of the personal values with that of business' creates a synergy that ensures the long-term viability of the business.

Finally, from a managerial perspective, the paper provides a map of managerial practices for value creation in circular business models by considering the peculiarities of a set of relevant internal and external contextual factors. In essence, we partially provided evidence regarding how to design a business model from scratch and scale it over period of time. Accordingly, we have also informed the business model innovation research as the creation of entirely new business plans as a start-up falls under the business model innovation besides the transformation from old business model to new one (Geissdoerfer et al., 2018a, 2018b). We have also showed the relationship between the managerial practices as they appear to be mutually supportive. In terms of managerial commitment, it has been found essential for successful realization of circular business model through the value network. We have also highlighted the potential tensions and paradoxical nature of circular business model for managers to develop consciousness for timely mitigation of the unintended outcomes. Moreover, the insights presented in this paper along the value network dimension might be useful for practitioners to design viable circular business models. 


\section{Internal factors}

1.1 Strategic orientation is prospector: challenging the current paradigm and looking for new ways of doing business by being context sensitive. Profitability can be compromised at the expense of innovation and new business opportunities.

1.2 - Dynamic managerial capabilities (managerial competence-cross industrial expertise that shapes value creation through a synergy: Health care, chemistry engineering and architecture). Supplier integration capability. Adaptability to local settings.

1.3 - Experimentation (process-product innovation) and long R\&D process prior to commercialization. Support to employees' expertise development, enliven employee strengths to let them become independent business owners, as a part of regeneration. Feedback mechanism *Caution: Risk of costly capital commitment that can offset financial viability.

1.4 Company size: SME: Multiple tasks or positions for an employee. Autonomous-entrepreneurial oriented. Fewer resources. Company age: Reputation. Capabilities and organizational learning. Growing trust accordingly with vendor and customer base, as the history of the company develops.

\section{\begin{tabular}{|l|l}
\hline 2 & External factor \\
\hline
\end{tabular}}

2.1 - Local waste, local use. Distrustful local culture (can be linked to the history of Native Americans, religiously-held community). Independent: without contract. Low level of economic activity and support for region's economic development and local regeneration. Contributing to community development -70 percent of the income reserved for regional regeneration (through social responsibility, social recreational, and public space projects). Managing supplier accessibility (some suppliers does not have internet or phone-Amish cultural requirement) *Caution: Local waste valorization imposes vulnerability regarding business growth and production volume.

2.2 - Intellectual rights protection. Leveraging company history, commitment, and essence (company philosophy and authenticity based on circular economy) to compete.

2.3 - Specification sheets for suppliers mandated by the company (how to function sustainably). Ten to 20 acres of restricted land for each supplier, with lighter equipment, mostly relying on human force (to guarantee a minimum impact on the environment). Certifications: (i) For product outgas test - California Air Quality VOC Standards; and (ii) Cradle-to-Cradle, B-Corp certifications relying on third-party audit. Workplace safety: S-H-A-R-P Award, Safety and Health Achievement Recognition Program from OSHA.

\section{Managerial Practices}

\begin{tabular}{l|l}
1 & - Innovating the process to reduce energy
\end{tabular} consumption and assist production by $100 \%$ solar power on site. No water is used for production (eliminated), yet there is proactive involvement at water-related social projects.

2 - Biodegradable material to be included in a closedloop. Built-in benefits of using natural material with the original purpose (biomimicry). Recycling of the natural waste as a value driver. *Caution: potential risk of eutrophication (surpassing the limit of absorptive capacity of biological nutrients, which might negatively affect the natural life (overly enriched in terms of nutrients and minerals).

$3,4, \quad$ - Design for biodegradability. Design of biological

5,6 and technical cycles. Design for product attachment and trust. Design for biomimicry. Design for local value chain. Design for recycling/upcycling. - Training more than 1,000 loggers from 250 suppliers regarding sustainability, quality management, and waste material specifications. Financially supporting for regeneration.

\begin{tabular}{l|l}
\hline 8 & - A total of 250 suppliers ( $90 \%$ within 50 miles) of
\end{tabular} tree bark waste material without contract. Very intimate, informal, personally engaged

communication. Mutual trust and respect that leads collaboration without contract. Transparency and clean process through monetary transactions.

9 - Managerial commitment in terms of willpower; explicit actions; and historically supported, consistent line of activities. Entrepreneurial oriented. Coaching and visionary leadership, caring and empathy for stakeholders. Sharp perception, and awareness of, strategic developments (training the suppliers). Bold decisions, not being driven by profit, but by balance (such as giving 70 percent of income back to the community). Authenticity. Releasing and encouraging the employee to start their own business as a part of regeneration.

\section{Value Creation in}

Circular Business Model

-Valorization of the natural local waste for regional socio-economic regeneration

- The fit and adaptability of managerial practices to the context - Sustainable behaviors of supply chain actors

Figure 3: Contextual factors and managerial practices mapped onto the dimensions of the theoretical framework. 


\section{Conclusions, limitations and avenues for further research}

The paper consolidated a theoretical conceptual framework that integrates the managerial practices of a value network dimension proposed by Urbinati et al. (2017) and Ünal et al., (2018), with internal and external contextual factors identified through business model design and innovation research. In particular, the proposed framework was created by leveraging previous literature on circular economy and business models, as well as those of organizational behaviour and social psychology.

We believe no single theory or literature can explain value creation in a circular business model. Therefore, the study empirically used a SME from the US that operates in the building sector. The case company has won an award as best $\mathrm{C} 2 \mathrm{C}$ practice, which strengthened the insights and contributions that the study presents.

The proposed theoretical framework might be helpful for both academicians and practitioners by having implications that span firms and theories. However, we underline the fact that our framework should be further refined and consolidated. For academicians, the study aims to present a comprehensive understanding and map of the role of key resources, activities and supply chain partners for value creation in circular business models. It does so within a clear and dynamic contextual (internal and external) environment. This approach goes beyond just understanding circular business models from materialistic and resources perspectives. Accordingly, this study contributes to circular business model research by adopting a broader interdisciplinary approach toward the concepts of value and value creation.

Business managers can utilize our research to redefine or transform their existing business model to enhance its degree of circularity or create a new business model by looking carefully at the influence of internal and external contextual factors. In particular, our study may provide a set of insights for managers, especially those in charge of sustainability and environmental responsibility, and examples of managerial practices implementation for creating value in circular business models into the building sector.

For the building sector, recycling natural, local waste is essential for circular business models by considering the impact on stakeholders. In this respect, designing for biomimicry can be helpful to facilitate creating value. In addition, our results show that circular economy in the building sector requires business model adaptability in terms of the value creation process, shaping a circular business model based on internal and external contextual conditions, and regenerating natural waste through aligning managerial practices, sociocultural and socioeconomic settings, and sustainable behaviours among supply chain actors. Additionally, the nature of the building sector indicates a large network of suppliers-collaborators-employees, longer lifecycles of products and higher economic rents. Therefore, this study shows that a circular business model provides robust opportunities for regional socioeconomic regeneration by co-creating shared value (Porter and Kramer, 2011). Also, several tensions have been observed as inherent part of circular business models, so can hamper the viability of the concept if not well understood and mitigated properly.

Having created and consolidated a theoretical framework for value creation in circular business models, this research has some limitations. First, we only focused on the biological materials, whereas technological materials are equally important. This is a persistent gap in literature and should be addressed by future research. Second, the study adopts a single case study, yet presents ample learning opportunities with in-depth analysis. Further research should refine and consolidate our framework within larger samples to strengthen the generalizability. In addition, geography (location and cultural settings) is a promising area as a further avenue of 
1 research, in terms of how value creation in circular economy changes in different contexts. As 2 such, the theoretical framework presented in this paper could be used in different industries with 3 a statistically significant sample size to further analyze with a quantitative approach the 4 constructs that the framework suggests. 


\section{References}

Amit, R., Zott, C., 2001. Value creation in e-business. Strateg. Manag. J. 22, 493-520. doi:10.1002/smj.187

Bocken, N.M.P., Schuit, C.S.C., Kraaijenhagen, C., 2018. Experimenting with a circular business model: Lessons from eight cases. Environ. Innov. Soc. Transitions. doi:10.1016/j.eist.2018.02.001

Bocken, N.M.P., Schuit, C.S.C., Kraaijenhagen, C., 2018. Experimenting with a circular business model: Lessons from eight cases. Environ. Innov. Soc. Transitions. doi:10.1016/j.eist.2018.02.001

Bougrain, F., Haudeville, B., 2002. Innovation, collaboration and SMEs internai research capacities. Res. Policy. doi:10.1016/S0048-7333(01)00144-5

Bourguignon, D., 2016. Closing the loop New circular economy package. Eur. Parliam. Res. Serv. 9. doi:10.1111/j.1742-1241.2010.02575.x

Bouwman, H., De Vos, H., Haaker, T., 2008. Mobile service innovation and business models, Mobile Service Innovation and Business Models. doi:10.1007/978-3-540-79238-3

Bouwman, H., Nikou, S., Molina-Castillo, F.J., de Reuver, M., 2018. The impact of digitalization on business models. Digit. Policy, Regul. Gov. doi:10.1108/DPRG-07-20170039

Chesbrough, H.W., 1999. The Organizational Impact of Technological Change: a Comparative Theory of National Institutional Factors. Ind. Corp. Chang. 8, 447-485. doi:doi: 10.1093/icc/8.3.447

Corbin, J.M., Strauss, A., 1990. Grounded theory research: Procedures, canons, and evaluative criteria. Qual. Sociol. doi:10.1007/BF00988593

D’Amato, A., Roome, N., 2009. Toward an integrated model of leadership for corporate responsibility and sustainable development: a process model of corporate responsibility beyond management innovation. Corp. Gov. 9, 421-434. doi:10.1108/14720700910984972

De los Rios, I.C., Charnley, F.J.S., 2017. Skills and capabilities for a sustainable and circular economy: The changing role of design. J. Clean. Prod. 160, 109-122. doi:10.1016/j.jclepro.2016.10.130

Doz, Y., Kosonen, M., 2008. The Dynamics of Strategic Agility: Nokia's Rollercoaster Experience. Calif. Manage. Rev. 50, 95-118. doi:10.2307/41166447

European Commission, 2018. Report on Critical Raw Materials and the Circular Economy. Comm. Staff Work. Doc.

Foss, N.J., Saebi, T., 2018. Business models and business model innovation: Between wicked and paradigmatic problems. Long Range Plann. doi:10.1016/j.1rp.2017.07.006

Foss, N.J., Saebi, T., 2017. Fifteen Years of Research on Business Model Innovation: How Far Have We Come, and Where Should We Go? J. Manage. 43, 200-227. doi: $10.1177 / 0149206316675927$ 
Fritscher, B., Pigneur, Y., 2010. Supporting business model modelling: A compromise between creativity and constraints, in: Lecture Notes in Computer Science (Including Subseries Lecture Notes in Artificial Intelligence and Lecture Notes in Bioinformatics). doi:10.1007/978-3-642-11797-8_3

Geissdoerfer, M., Morioka, S.N., de Carvalho, M.M., Evans, S., 2018a. Business models and supply chains for the circular economy. J. Clean. Prod. 190, 712-721. doi:10.1016/j.jclepro.2018.04.159

Geissdoerfer, M., Vladimirova, D., Evans, S., 2018b. Sustainable business model innovation: A review. J. Clean. Prod. 198, 401-416. doi:10.1016/j.jclepro.2018.06.240

Ghisellini, P., Cialani, C., Ulgiati, S., 2014. A review on circular economy: The expected transition to a balanced interplay of environmental and economic systems. J. Clean. Prod. doi:10.1016/j.jclepro.2015.09.007

Glaser, B., Strauss, A., 1967. Applying Grounded Theory. The discovery of grounded theory: strategies of qualitative research. Grounded Theory Rev.

Go, T.F., Wahab, D.A., Rahman, M.N.A., Ramli, R., Azhari, C.H., 2011. Disassemblability of end-of-life vehicle: a critical review of evaluation methods. J. Clean. Prod. 19, 1536-1546. doi:10.1016/j.jclepro.2011.05.003

Goldsworthy, K., 2013. Design for Cyclability: Pro-active approaches for maximising material recovery. Mak. Futur. 3.

Gregson, N., Crang, M., Fuller, S., Holmes, H., 2015. Interrogating the circular economy: the moral economy of resource recovery in the EU. Econ. Soc. 44, 218-243. doi:10.1080/03085147.2015.1013353

Guba, E.G., Guba, Y.A.L., Lincoln, Y.S., 1994. Competing Paradigms in Qualitative Research. Handb. Qual. Res. doi:http://www.uncg.edu/hdf/facultystaff/Tudge/Guba\%20\&\%20Lincoln\%201994.pdf

Haaker, T., Bouwman, H., Janssen, W., de Reuver, M., 2017. Business model stress testing: A practical approach to test the robustness of a business model. Futures. doi:10.1016/j.futures.2017.04.003

Hueske, A.K., Endrikat, J., Guenther, E., 2015. External environment, the innovating organization, and its individuals: A multilevel model for identifying innovation barriers accounting for social uncertainties. J. Eng. Technol. Manag. - JET-M 35, 45-70. doi:10.1016/j.jengtecman.2014.10.001

Ingrao, C., Scrucca, F., Tricase, C., Asdrubali, F., 2016. A comparative Life Cycle Assessment of external wall-compositions for cleaner construction solutions in buildings. J. Clean. Prod. 124, 283-298. doi:10.1016/j.jclepro.2016.02.112

Intini, F., Kühtz, S., 2011. Recycling in buildings: An LCA case study of a thermal insulation panel made of polyester fiber, recycled from post-consumer PET bottles. Int. J. Life Cycle Assess. 16, 306-315. doi:10.1007/s11367-011-0267-9

Karakaya, E., Hidalgo, A., Nuur, C., 2015. Motivators for adoption of photovoltaic systems at 
grid parity: A case study from Southern Germany. Renew. Sustain. Energy Rev. doi:10.1016/j.rser.2014.11.077

Kendall, J., 1999. Axial coding and the grounded theory controversy. West. J. Nurs. Res. doi:10.1177/01939459922044162

Khasreen, M.M., Banfill, P.F.G., Menzies, G.F., 2009. Life-cycle assessment and the environmental impact of buildings: A review. Sustainability 1, 674-701. doi:10.3390/su1030674

Kiesler, C.A., 1971. The psychology of commitment: Experiments linking behavior to belief. Academic Press, New York.

Klein, K.J., Sorra, J.S., 1996. The challenge of innovation implementation. Acad. Manag. Rev. 21, 1055-1080. doi:10.5465/AMR.1996.9704071863

Korhonen, J., Nuur, C., Feldmann, A., Birkie, S.E., 2018. Circular economy as an essentially contested concept. J. Clean. Prod. 175, 544-552. doi:10.1016/j.jclepro.2017.12.111

Küçüksayraç, E., Keskin, D., Brezet, H., 2015. Intermediaries and innovation support in the design for sustainability field: cases from the Netherlands, Turkey and the United Kingdom. J. Clean. Prod. 101, 38-48. doi:10.1016/j.jclepro.2015.03.078

Lämsä, A.-M., Savolainen, T., 2000. The nature of managerial commitment to strategic change. Leadersh. Organ. Dev. J. 21, 297-306. doi:10.1108/01437730010372822

Lapko, Y., Trianni, A., Nuur, C., Masi, D., 2018. In Pursuit of Closed-Loop Supply Chains for Critical Materials: An Exploratory Study in the Green Energy Sector. J. Ind. Ecol. doi:10.1111/jiec.12741

Lee, S., Park, G., Yoon, B., Park, J., 2010. Open innovation in SMEs-An intermediated network model. Res. Policy. doi:10.1016/j.respol.2009.12.009

Leising, E., Quist, J., Bocken, N., 2018. Circular Economy in the building sector: Three cases and a collaboration tool. J. Clean. Prod. 176, 976-989. doi:10.1016/j.jclepro.2017.12.010

Lewandowski, M., 2016. Designing the business models for circular economy-towards the conceptual framework. Sustain. doi:10.3390/su8010043

Li, H., Bao, W., Xiu, C., Zhang, Y., Xu, H., 2010. Energy conservation and circular economy in China's process industries. Energy 35, 4273-4281. doi:10.1016/j.energy.2009.04.021

Lieder, M., Rashid, A., 2016. Towards circular economy implementation: A comprehensive review in context of manufacturing industry. J. Clean. Prod. doi:10.1016/j.jclepro.2015.12.042

Linder, M., Williander, M., 2017. Circular Business Model Innovation: Inherent Uncertainties. Bus. Strateg. Environ. 26, 182-196. doi:10.1002/bse.1906

Lindgren, P., Rasmussen, O.H., 2013. The business model cube. Educ. Next. doi: $10.1145 / 2228360.2228567$

Mang, P., Reed, B., 2015. The nature of positive. Build. Res. Inf. 43, 7-10. 
Manninen, K., Koskela, S., Antikainen, R., Bocken, N., Dahlbo, H., Aminoff, A., 2018. Do circular economy business models capture intended environmental value propositions? J. Clean. Prod. 171, 413-422. doi:10.1016/j.jclepro.2017.10.003

Martins, L.L., Rindova, V.P., Greenbaum, B.E., 2015. Unlocking the hidden value of concepts: A cognitive approach to business model innovation. Strateg. Entrep. J. doi:10.1002/sej.1191

Massa, L., Tucci, L.C., 2013. Business Model Innovation. Oxford Handb. Innov. Manag. doi:10.1002/9781118466421.ch4

Mayyas, A., Qattawi, A., Omar, M., Shan, D., 2012. Design for sustainability in automotive industry: A comprehensive review. Renew. Sustain. Energy Rev. doi:10.1016/j.rser.2012.01.012

McDonough, W., Braungart, M., 2002. Cradle to Cradle: Remaking the way we make things. Chem. Eng. News 193. doi:10.1177/0276146704264148

Merli, R., Preziosi, M., Acampora, A., 2018. How do scholars approach the circular economy? A systematic literature review. J. Clean. Prod. doi:10.1016/j.jclepro.2017.12.112

Merli, R., Preziosi, M., Acampora, A., 2017. How do scholars approach the circular economy? A systematic literature review. J. Clean. Prod. doi:10.1016/j.jclepro.2017.12.112

Meyer, J.P., Stanley, D.J., Herscovitch, L., Topolnytsky, L., 2002. Affective, continuance, and normative commitment to the organization: A meta-analysis of antecedents, correlates, and consequences. J. Vocat. Behav. doi:10.1006/jvbe.2001.1842

Miles, R.E., Snow, C.C., Meyer, A.D., Coleman, H.J., 1978. Organizational strategy, structure, and process. Acad. Manage. Rev. doi:10.5465/AMR.1978.4305755

Moreno, M., De los Rios, C., Rowe, Z., Charnley, F., 2016. A conceptual framework for circular design. Sustain. 8. doi:10.3390/su8090937

Morris, M., Schindehutte, M., Allen, J., 2005. The entrepreneur's business model: Toward a unified perspective. J. Bus. Res. 58, 726-735. doi:10.1016/j.jbusres.2003.11.001

Morse, J., 2000. Determining Sample Size. Qual. Health Res. 10, 3-5.

Morse, J., 1998. Designing Funded Qualitative Research, in: Handbook of Qualitative Research. doi:10.1017/CBO9781107415324.004

Mowday, R.T.., Porter, L.W.., Steers, R.M.., 1983. Employee-Organization linkages: The psychology of commitment, absenteeism, and turnover, American Journal of Socioty. doi: $10.2307 / 2068333$

Murray, A., Skene, K., Haynes, K., 2015. The Circular Economy: An Interdisciplinary Exploration of the Concept and Application in a Global Context. J. Bus. Ethics 0-37. doi:10.1007/s10551-015-2693-2

Narula, R., 2004. R\&D collaboration by SMEs: New opportunities and limitations in the face of globalisation. Technovation 24, 153-161. doi:10.1016/S0166-4972(02)00045-7 
Österwalder, A., 2004. The Business Model Ontology - A Proposition in a Design Science Approach. Business. doi:10.1111/j.1467-9310.2010.00605.x

Osterwalder, A., Pigneur, Y., 2010. Business Model Generation: A Handbook for Visionaries, Game Changers, and Challengers, A handbook for visionaries, game changers, and challengers. doi:10.1523/JNEUROSCI.0307-10.2010

Parkinson, H.J., Thompson, G., 2003. Analysis and taxonomy of remanufacturing industry practice. Proc. Inst. Mech. Eng. Part E J. Process Mech. Eng. 217, 243-256. doi:10.1243/095440803322328890

Peck, D., 2016. Prometheus Missing. Critical Materials and Product Design. TU Delft Univ. doi:10.4233/uuid:a6a69144- c78d-4feb-8df7-51d1c20434ea

Phillips, C.F., Scherer, F.M., 1971. Industrial Market Structure and Economic Performance. Bell J. Econ. Manag. Sci. 2, 683. doi:10.2307/3003013

Pomponi, F., Moncaster, A., 2017. Circular economy for the built environment: A research framework. J. Clean. Prod. 143, 710-718. doi:10.1016/j.jclepro.2016.12.055

Porter, M., 1979. How Competitive Forces Shape Strategy. Harv. Bus. Rev. 57, 137-145. doi:10.1097/00006534-199804050-00042

Porter, M.E., Kramer, M.R., 2011. Creating shared value. Harv. Bus. Rev. 89. doi:10.1108/09600039410055963

Ramus, C.A., Steger, U., 2000. The roles of supervisory support behaviors and environmental policy in employee "ecoinitiatives" at leading-edge European companies. Acad. Manag. J. 43, 605-626. doi:10.2307/1556357

Reed, B., 2007. Forum: Shifting from "sustainability" to regeneration. Build. Res. Inf. 35, 674680. doi:10.1080/09613210701475753

Reichers, A.E., 1985. A review and reconceptualization of organizational commitment. Acad. Manage. Rev. doi:10.5465/AMR.1985.4278960

Reijnders, L., 2008. Are emissions or wastes consisting of biological nutrients good or healthy? J. Clean. Prod. doi:10.1016/j.jclepro.2008.02.003

Rizos, V., Behrens, A., van der Gaast, W., Hofman, E., Ioannou, A., Kafyeke, T., Flamos, A., Rinaldi, R., Papadelis, S., Hirschnitz-Garbers, M., Topi, C., 2016. Implementation of circular economy business models by small and medium-sized enterprises (SMEs): Barriers and enablers. Sustain. 8. doi:10.3390/su8111212

Salancik, G.R., 1977. Commitment and the control of organizational behavior and belief. New Dir. Organ. Behav.

Scherer, F.M., Ross, D., 1990. Industrial Market Structure and Economic Performance. SSRN eLibrary.

Schneider, S.., Spieth, P., 2013. Business Model Innovation: Towards an Integrated Future Research Agenda. Int. J. Innov. Manag. 17, 1340001. doi:doi:10.1142/S136391961340001X 
Singh, J., Ordoñez, I., 2016. Resource recovery from post-consumer waste: important lessons for the upcoming circular economy. J. Clean. Prod. 134, 342-353. doi:10.1016/j.jclepro.2015.12.020

Solaimani, S., Heikkilä, M., Bouwman, H., 2018. Business Model Implementation within Networked Enterprises: A Case Study on a Finnish Pharmaceutical Project. Eur. Manag. Rev. doi:10.1111/emre.12124

Stahel, W., 1994. The Utilization-Focused Service Economy: Resource Efficiency and ProductLife Extension, in: The Greening of Industrial Ecosystems. pp. 178-190. doi: $10.17226 / 2129$.

Teece, D.J., 2017. Business models and dynamic capabilities. Long Range Plann. doi:10.1016/j.lrp.2017.06.007

Tellis, W.M., 1997. The Qualitative Report Application of a Case Study Methodology Application of a Case Study Methodology. Qual. Rep. doi:3.3

Terziovski, M., 2010. Innovation practice and its performance implications in small and medium enterprises (SMEs) in the manufacturing sector: a resource-based view. Strateg. Manag. J. n/a-n/a. doi:10.1002/smj.841

Tongur, S., Engwall, M., 2014. The business model dilemma of technology shifts. Technovation. doi:10.1016/j.technovation.2014.02.006

Tukker, A., 2015. Product services for a resource-efficient and circular economy - A review. J. Clean. Prod. doi:10.1016/j.jclepro.2013.11.049

Tukker, A., 2013. Product services for a resource-efficient and circular economy - a review. J. Clean. Prod. 97, 76-91. doi:10.1016/j.jclepro.2013.11.049

Ünal, E., Shao, J., 2018. A Taxonomy of Circular Economy Implementation Strategies for Manufacturing Firms: Analysis of 391 Cradle-to-Cradle Products. J. Clean. Prod. doi:10.1016/j.jclepro.2018.11.291

Ünal, E., Urbinati, A., Chiaroni, D., 2018. Managerial practices for designing circular economy business models. J. Manuf. Technol. Manag. JMTM-02-2018-0061. doi:10.1108/JMTM-022018-0061

Urbinati, A., Chiaroni, D., Chiesa, V., 2017a. Towards a new taxonomy of circular economy business models. J. Clean. Prod. 168, 487-498. doi:10.1016/j.jclepro.2017.09.047

Urbinati, A., Chiaroni, D., Chiesa, V., 2017b. Towards a new taxonomy of circular economy business models. J. Clean. Prod. doi:10.1016/j.jclepro.2017.09.047

Urbinati, A., Chiaroni, D., Chiesa, V., Franzò, S., Frattini, F., 2018. An Exploratory Analysis on the Contextual Factors that Influence Disruptive Innovation: The Case of Uber. Int. J. Innov. Technol. Manag. 1850024. doi:10.1142/S0219877018500244

Vermeulen, W.J.V., 2015. Self-governance for sustainable global supply chains: Can it deliver the impacts needed? Bus. Strateg. Environ. 24, 73-85. doi:10.1002/bse.1804

Visnjic, I., Neely, A., Jovanovic, M., 2018. The path to outcome delivery: Interplay of service 
market strategy and open business models. Technovation 72-73, 46-59.

doi:10.1016/j.technovation.2018.02.003

Weber, R.P., 1990. Basic content analysis: Second edition, Sage. doi:10.2307/2289192

Williams, A., 2007. Product service systems in the automobile industry: contribution to system innovation? J. Clean. Prod. 15, 1093-1103. doi:10.1016/j.jclepro.2006.05.034

Yin, R.K., 2003. Case Study Research . Design and Methods. SAGE Publ. doi:10.1097/FCH.0b013e31822dda9e

Yin, R.K., 1994. Case Study Research-Design and Methods, Sage Publications.

Yu, D., Hang, C.C., 2010. A Reflective Review of Disruptive Innovation Theory. Int. J. Manag. Rev. doi:10.1111/j.1468-2370.2009.00272.x

Zhu, Q., Geng, Y., Lai, K. hung, 2011. Environmental supply chain cooperation and its effect on the circular economy practice-performance relationship among Chinese manufacturers. J. Ind. Ecol. 15, 405-419. doi:10.1111/j.1530-9290.2011.00329.x

Zhu, Q., Geng, Y., Lai, K. hung, 2010. Circular economy practices among Chinese manufacturers varying in environmental-oriented supply chain cooperation and the performance implications. J. Environ. Manage. 91, 1324-1331. doi:10.1016/j.jenvman.2010.02.013

Zink, T., Geyer, R., 2017. Circular Economy Rebound. J. Ind. Ecol. 21, 593-602. doi: $10.1111 /$ jiec. 12545

Zott, C., Amit, R., 2010. Business model design: An activity system perspective. Long Range Plann. 43, 216-226. doi:10.1016/j.lrp.2009.07.004 


\section{Appendix}

\section{Table 1A. Interview Protocol}

\begin{tabular}{|c|c|c|}
\hline \multirow{6}{*}{\multicolumn{2}{|c|}{ Managerial Practices }} & $\begin{array}{l}\text { Establishment of effective communication with suppliers, retailers, and end-of-life } \\
\text { materials managers (such as the waste industry), as well as with all the actors involved in } \\
\text { the supply chain: } \\
\text { - How do you work with your suppliers? } \\
\text { - How many suppliers do you have? } \\
\text { - } \quad \text { What is the profile of your suppliers? } \\
\text { - How do you communicate with your suppliers? } \\
\text { - How effectively do you think you communicate with the suppliers? } \\
\text { - } \quad \text { Do you give any training to your suppliers regarding the circular economy and } \\
\text { sustainability? }\end{array}$ \\
\hline & & $\begin{array}{l}\text { Support of all partners to develop awareness and new skills, rendering the business model } \\
\text { more viable, or circular, for all actors involved in the supply chain: } \\
\text { - } \quad \text { How do you support your suppliers in terms of developing awareness and new skills? }\end{array}$ \\
\hline & & $\begin{array}{l}\text { Energy efficiency-driven practices to reduce emissions and environmental footprint: } \\
\text { - In terms of energy efficiency, what actions do you take? } \\
\text { - } \quad \text { Are you using any kind of renewable energy? } \\
\text { - } \quad \text { Do you use water in your production process? }\end{array}$ \\
\hline & & $\begin{array}{l}\text { Friendly material usage practices, such as natural, recyclable, durable, easy to separate: } \\
\text { - What waste are you recycling? Are you including it in a biological or technical cycle? } \\
\text { - } \quad \text { Is the building material you produce natural/biodegradable? } \\
\text { - } \quad \text { What happens after the end of the useful life of the product? }\end{array}$ \\
\hline & & $\begin{array}{l}\text { DfX practices: } \\
\text { - How do you design your products based on circular economy? } \\
\text { - } \quad \text { What do you consider when you design your products? }\end{array}$ \\
\hline & & $\begin{array}{l}\text { Managerial commitment or leadership: } \\
\text { - How do you manage your employees and other stakeholders? } \\
\text { - How did you become aware of this circular-economy business opportunity? } \\
\text { - } \quad \text { How did you decide to give back } 70 \text { percent of your income back to the society? } \\
\text { - How do you use your resources to execute a circular-economy business plan? } \\
\text { To what extent are you engaged in circular economy activities? }\end{array}$ \\
\hline \multirow[t]{3}{*}{$\begin{array}{c}\text { Contextual } \\
\text { Factors }\end{array}$} & \multirow[t]{3}{*}{ Internal } & $\begin{array}{l}\text { Strategic orientation: } \\
\text { - } \quad \text { How do you position yourself in the market and how do you compete against rivals? } \\
\text { - } \quad \text { Are you facing any technological, administrative or entrepreneurial problem? If yes, } \\
\text { how do you solve it? } \\
\text { - } \quad \text { How do you describe your market share? } \\
\text { - } \quad \text { What is your quality and pricing strategy? } \\
\text { - } \quad \text { Are you following and adopting recent developments at the market? } \\
\text { - } \quad \text { How profitable is your business? } \\
\text { - } \quad \text { Are you investing on new technologies or products? If yes or no, why? }\end{array}$ \\
\hline & & $\begin{array}{l}\text { Industrial capabilities: } \\
\text { - } \quad \text { What are the backgrounds of the co-founders? } \\
\text { - } \quad \text { How did you sense/identify the circular-economy business opportunity? } \\
\text { - } \quad \text { How did you decide in which technology to invest and shape your business model? } \\
\text { - } \quad \text { How these competencies and background helped you design a circular business model? } \\
\text { - } \quad \text { How did you sustain supplier membership with your company? }\end{array}$ \\
\hline & & Learning and training mechanisms: \\
\hline
\end{tabular}




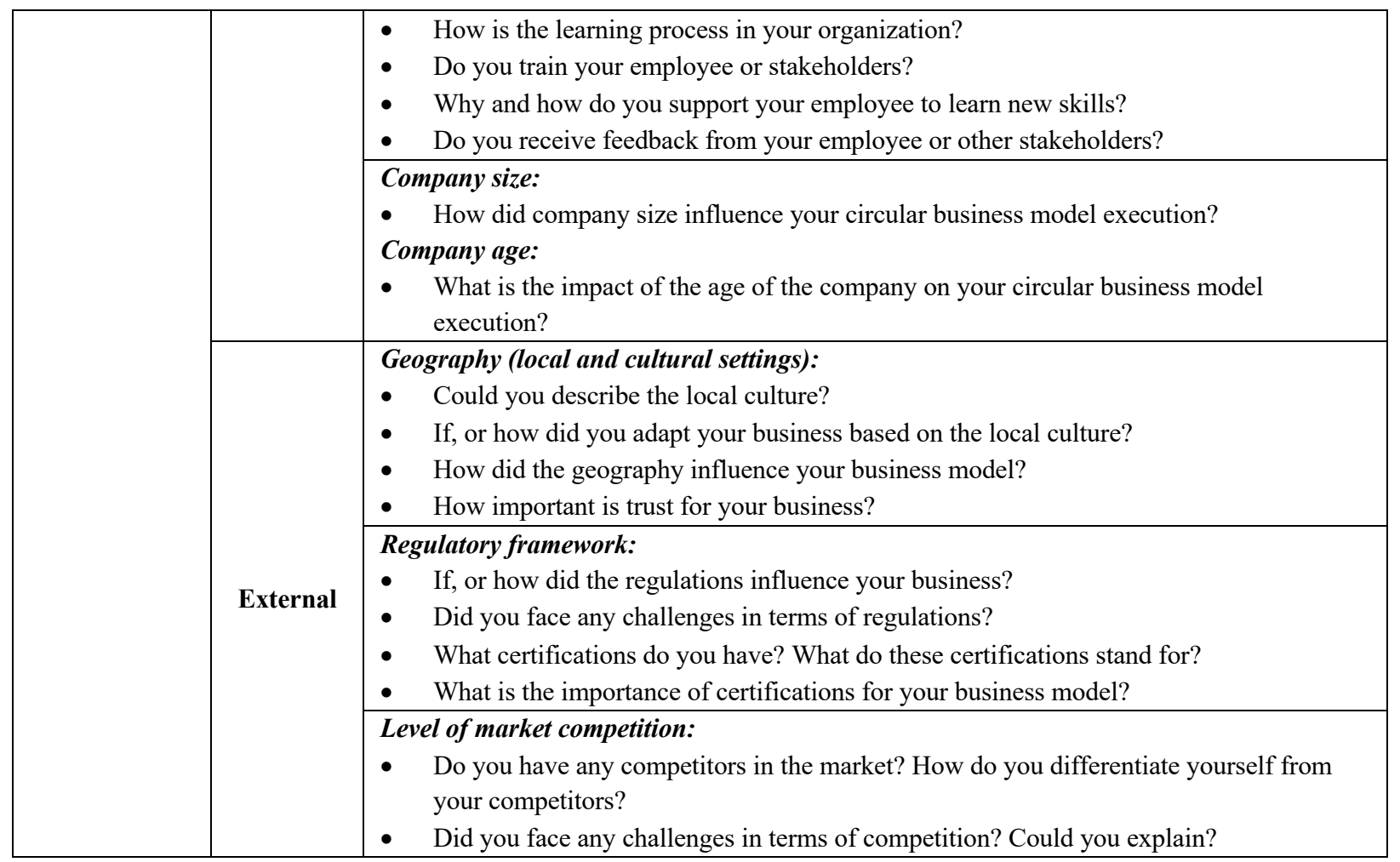

